\title{
Statins: Antimicrobial resistance breakers or makers?
}

\author{
Humphrey Ko ${ }^{\text {Corresp., }}{ }^{1,2}$, Ricky Lareu ${ }^{1,2}$ ， Brett Dix ${ }^{1}$, Jeffery Hughes ${ }^{1}$ \\ ${ }^{1}$ School of Pharmacy, Faculty of Health Sciences, Curtin University, Perth, Western Australia, Australia \\ 2 Curtin Health Innovation Research Institute (CHIRI) Biosciences Research Precinct, Curtin University, Perth, Western Australia, Australia \\ Corresponding Author: Humphrey Ko \\ Email address: h.ko2@student.curtin.edu.au
}

\section{INTRODUCTION}

The repurposing of non-antibiotic drugs as adjuvant antibiotics may help break antimicrobial resistance (AMR). Statins are commonly prescribed worldwide to lower cholesterol. They also possess qualities of AMR "breakers", namely direct antibacterial activity, synergism with antibiotics, and ability to stimulate the host immune system. However, statins' role as AMR breakers may be limited. Their current extensive use for cardiovascular protection might result in selective pressures for resistance, ironically causing statins to be AMR "makers" instead. This review examines statins' potential as AMR breakers, probable AMR makers, and identifies knowledge gaps in a statin-bacteria-human-environment continuum. The most suitable statin for repurposing is identified, and a mechanism of antibacterial action is postulated based on structure-activity relationship analysis.

\section{METHODS}

A literature search using keywords "statin" or "statins" combined with "minimum inhibitory concentration" (MIC) was performed in six databases on $7^{\text {th }}$ April 2017. After screening 793 abstracts, 16 relevant studies were identified. Unrelated studies on drug interactions; antifungal or antiviral properties of statins; and antibacterial properties of mevastatin, cerivastatin, antibiotics, or natural products were excluded. Studies involving only statins currently registered for human use were included.

\section{RESULTS}

Against Gram-positive bacteria, simvastatin generally exerted the greatest antibacterial activity (lowest MIC) compared to atorvastatin, rosuvastatin, and fluvastatin. Against Gram-negative bacteria, atorvastatin generally exhibited similar or slightly better activity compared to simvastatin, but both were more potent than rosuvastatin and fluvastatin.

\section{DISCUSSION}

Statins may serve as AMR breakers by working synergistically with existing topical antibiotics, attenuating virulence factors, boosting human immunity, or aiding in wound healing. It is probable that statins' mechanism of antibacterial activity involves interference of bacterial cell regulatory functions via binding and disrupting cell surface structures such as wall teichoic acids, lipoteichoic acids, lipopolysaccharides, and/or surface proteins. The widespread use of statins for cardiovascular protection may favor selective pressures or co-selection for resistance, including dysbiosis of the human gut microbiota, sublethal plasma concentrations in bacteremic patients, and statin persistence in the environment, all possibly culminating in AMR. 


\section{CONCLUSION}

Simvastatin appears to be the most suitable statin for repurposing as a novel adjuvant antibiotic. Current evidence better supports statins as potential AMR breakers, but their role as plausible AMR makers cannot be excluded. Elucidating the mechanism of statins' antibacterial activity is perhaps the most important knowledge gap to address as this will likely clarify statins' role as AMR breakers or makers. 
1 Article Title: Statins: Antimicrobial resistance breakers or makers?

2 Authors: Humphrey Ko ${ }^{1,2}$, Ricky Lareu ${ }^{1,2}$, Brett Dix ${ }^{1}$, Jeffery Hughes ${ }^{1}$.

$3{ }^{1}$ School of Pharmacy, Faculty of Health Sciences, Curtin University, Perth, Western Australia, 4 Australia.

$5{ }^{2}$ Curtin Health Innovation Research Institute (CHIRI) Biosciences Research Precinct, Curtin

6 University, Perth, Western Australia, Australia.

7 Corresponding author: Humphrey Ko

8 Email address: h.ko2@student.curtin.edu.au 


\section{ABSTRACT}

INTRODUCTION

11 The repurposing of non-antibiotic drugs as adjuvant antibiotics may help break antimicrobial resistance (AMR). Statins are commonly prescribed worldwide to lower cholesterol. They also possess qualities of AMR “breakers", namely direct antibacterial activity, synergism with antibiotics, and ability to stimulate the host immune system. However, statins' role as AMR breakers may be limited. Their current extensive use for cardiovascular protection might result in selective pressures for resistance, ironically causing statins to be AMR "makers" instead. This review examines statins' potential as AMR breakers, probable AMR makers, and identifies knowledge gaps in a statin-bacteria-human-environment continuum. The most suitable statin for repurposing is identified, and a mechanism of antibacterial action is postulated based on structure-activity relationship analysis.

\section{METHODS}

A literature search using keywords "statin" or "statins" combined with "minimum inhibitory concentration" (MIC) was performed in six databases on $7^{\text {th }}$ April 2017. After screening 793 abstracts, 16 relevant studies were identified. Unrelated studies on drug interactions; antifungal or antiviral properties of statins; and antibacterial properties of mevastatin, cerivastatin, antibiotics, or natural products were excluded. Studies involving only statins currently registered for human use were included.

\section{RESULTS}

Against Gram-positive bacteria, simvastatin generally exerted the greatest antibacterial activity bacteria, atorvastatin generally exhibited similar or slightly better activity compared to simvastatin, but both were more potent than rosuvastatin and fluvastatin. 
34 Statins may serve as AMR breakers by working synergistically with existing topical antibiotics,

35 attenuating virulence factors, boosting human immunity, or aiding in wound healing. It is

36 probable that statins' mechanism of antibacterial activity involves interference of bacterial cell

37 regulatory functions via binding and disrupting cell surface structures such as wall teichoic acids,

38 lipoteichoic acids, lipopolysaccharides, and/or surface proteins. The widespread use of statins for

39 cardiovascular protection may favor selective pressures or co-selection for resistance, including

40 dysbiosis of the human gut microbiota, sublethal plasma concentrations in bacteremic patients,

41 and statin persistence in the environment, all possibly culminating in AMR.

42 CONCLUSION

43 Simvastatin appears to be the most suitable statin for repurposing as a novel adjuvant antibiotic.

44 Current evidence better supports statins as potential AMR breakers, but their role as plausible

45 AMR makers cannot be excluded. Elucidating the mechanism of statins' antibacterial activity is

46 perhaps the most important knowledge gap to address as this will likely clarify statins' role as

47 AMR breakers or makers. 
Introduction

49 Antimicrobial resistance (AMR) occurs when microorganisms become immune to antimicrobials

50 via intrinsic resistance (possessing mechanisms which reduce intracellular concentrations of

51 antimicrobials or render antimicrobials ineffective); acquired resistance (gaining resistant genes

52 via mutation or horizontal gene transfer); or adaptive resistance (adapting to environmental stress

53 by altering gene expressions) (Canton et al. 2013; Fernandez et al. 2011). Selective pressures for

54 resistance can occur at both lethal and sublethal drug concentrations (Hughes \& Andersson

55 2017). When susceptible bacteria are exposed to antimicrobial concentrations within eight to ten

56 times above the minimum inhibitory concentration (MIC), AMR may occur due to the

57 propagation of pre-existing resistant mutant strains whilst the susceptible strains are killed

58 (Andersson \& Hughes 2014; Canton et al. 2013; Levison \& Levison 2009). At low antibiotic

59 concentrations (up to several hundred times below MIC), AMR proliferation may occur with the

60 growth of multiple new resistant mutant strains due to minute reductions in the growth rate of

61 susceptible bacteria (Andersson \& Hughes 2011; Andersson \& Hughes 2014; Kohanski et al.

62 2010).

63 In addition to antibiotics, it was found that exposure of bacteria to biocides, metals, and non-

64 antibiotic chemicals with antibacterial properties also contributed to AMR via co-selection of

65 resistant genes (Li et al. 2016; Singer et al. 2016; Wales \& Davies 2015). Co-selection protects a

66 bacterial strain against multiple antibiotic classes due to the selection of one gene which confers

67 multiple resistance mechanisms (cross-resistance), or the selection of physically linked genes

68 which collectively confer various resistance mechanisms (co-resistance) (Singer et al. 2016;

69 Wales \& Davies 2015). 
70 The World Health Organization has warned that with the rise of AMR, the world is moving

71 towards a post-antibiotic era whereby if last-line antibiotics become ineffective, common

72 infections and minor injuries may prove fatal (World Health Organization). In response to the

73 AMR threat, many countries have initiated a concerted "One Health" best practice approach to

74 suppress AMR, involving optimal use of antibiotics in humans and animals (World Health

75 Organization). It has been suggested that AMR may be impeded by the administration of certain

76 non-antibiotic drugs together with current antibiotic treatment (Brown 2015). These non-antibiotic

77 drugs may be repurposed (used to treat new conditions) to act as AMR "breakers" if they have

78 direct antibacterial activity, synergize with antibiotics, stimulate the host immune system, or

79 possess a combination of these properties (Brown 2015). Antihyperlipidemic agents 3-hydroxy-3-

80 methylglutaryl-coenzyme A (HMG-CoA) reductase inhibitors, commonly known as statins,

81 appear to possess the mentioned properties of AMR breakers and have been poised to be

82 repurposed as novel adjuvant antimicrobials (Hennessy et al. 2016).

83 Statins are one of the most commonly prescribed medicines in the world, with over 30 million

84 people in the United States and up to 200 million people worldwide taking statins daily to lower

85 cholesterol for primary and secondary prevention of cardiovascular diseases (Blaha \& Martin

86 2013). By competitively binding to HMG-CoA reductase in a dose-dependent manner, statins

87 inhibit the rate limiting step of the mevalonate pathway, thus diminishing cholesterol production

88 (Liao 2005). In the process however, important isoprenoid intermediates such as geranylgeranyl

89 pyrophosphate (GGPP) and farnesyl pyrophosphate (FPP) are also reduced, hence decreasing cell

90 signaling proteins (e.g. Ras, Rac, and Rho) and causing multiple cholesterol-independent

91 (pleiotropic) effects which are cardioprotective (e.g. antithrombotic, antioxidant, antiplatelet, and

92 endothelial protection) and immunomodulatory (e.g. anti-inflammatory and neutrophil 
93 extracellular trap [NET] production) (Chow et al. 2010; Gazzerro et al. 2012; Kozarov et al.

94 2014).

95 Research on statins originated with the intention of developing new antibiotics. In 1971,

96 Professor Akira Endo searched for new antibiotics with the hypothesis that fungi may produce

97 substances which inhibit HMG-CoA reductase, thereby killing microorganisms (Endo 2010). The

98 discovery of statins and their potent cholesterol-lowering abilities soon led to their clinical use in

99 preventing cardiovascular diseases instead (Endo 2010). In recent years however, interest

100 returned to the inherent antimicrobial effects of statins (Jerwood \& Cohen 2008).

101 Although statins possess the potential to be AMR breakers (direct antibacterial activity,

102 synergistic activity with antibiotics, and ability to stimulate the human immune system) (Brown

103 2015; Hennessy et al. 2016), they are currently extensively used to treat hypercholesterolemia (a

104 non-antimicrobial purpose). Prolonged exposure of bacterial populations to drugs with

105 antibacterial properties may expedite the death of susceptible bacteria, resulting in subsequent

106 dominance of resistant bacteria, regardless of the exposure being in humans, animals, or the

107 environment (Canton et al. 2013). The problem is likely to be compounded with recent guidelines

108 recommending the initiation of statins in adults aged 40 to 75 years with one or more

109 cardiovascular risk factors (US Preventive Services Task Force 2016), and evidence that the

110 benefits of statins for cardiovascular protection far outweigh their side effects (Collins et al.

111 2016).

112 This review examines the potential of statins as AMR breakers, which albeit promising, could be

113 limited by antibacterial resistance acquired via selective pressures and co-selection, ironically

114 culminating in statins contributing as AMR “makers” instead. Statins' potential roles as AMR 
115 breakers, AMR makers, and knowledge gaps were reviewed as a statin-bacteria-human-

116 environment continuum. From MIC data available in literature, the susceptibility of various

117 bacteria to individual statins may be ascertained to reveal the most suitable statin for repurposing

118 as a novel adjuvant antimicrobial. In addition, by comparing chemical structures of statins with

119 antibacterial activity against statins without antibacterial activity, a mechanism of antibacterial

120 action for statins was postulated.

\section{Methods}

\section{Literature search}

123 The keywords "statin" or "statins" were combined with "minimum inhibitory concentration" to

124 identify studies which reported MIC values of statins when tested against specific bacterial

125 strains. "Minimum inhibitory concentration" was used as a keyword instead of a general term

126 "antibacterial effect" because MIC values allow quantitative comparisons of antibacterial potency

127 between individual statins (Dafale et al. 2016). Moreover, exposure of susceptible bacteria to 128 antibacterial drug concentrations ranging from within eight to ten times above MIC to several

129 hundred times below MIC may contribute to selective pressures for resistance (Andersson \& 130 Hughes 2011; Levison \& Levison 2009). The search was performed by the primary investigator 131 (HK) in six databases on $7^{\text {th }}$ April 2017, namely the Cumulative Index to Nursing and Allied 132 Health Literature (CINAHL), Cochrane Library, Embase, PubMed, Google Scholar, and Web of 133 Science (Figure 1).

\section{Studies selection}

135 Screening the titles and abstracts of the initial 793 results identified from the keywords, 756

136 studies were excluded because they covered unrelated topics such as drug interactions; antifungal

137 or antiviral properties of statins; and antibacterial properties of mevastatin, cerivastatin, 
138 antibiotics, or natural products. Although antibacterial effects of mevastatin and cerivastatin have

139 been studied (Hennessy et al. 2016), they are not currently used clinically and were therefore

140 omitted in this review (Tobert 2003). Only antibacterial properties of atorvastatin (ATV),

141 fluvastatin (FLV), lovastatin (LVS), pitavastatin (PTV), pravastatin (PRV), rosuvastatin (RSV),

142 and simvastatin (SMV) were considered relevant for this review as these are currently registered

143 drugs for lowering cholesterol in humans, thus likely to affect the statin-bacteria-human-

144 environment continuum.

145 Upon reviewing the full text of the remaining 37 studies, 21 studies were further excluded as they 146 contained duplicate information; studied the effects of statins on infected cells instead of direct

147 bacterial exposure; or tested the combined effects of statins and antibiotics without reporting the

148 MIC of statins alone. The resultant 16 pertinent studies consisted of a thesis (Alshammari 2016),

149 a letter with unpublished MIC data (Bjorkhem-Bergman et al. 2011), a Turkish study with

150 relevant data in its English abstract (Coban et al. 2010), a patent application (Quivey 2014), a

151 review article with information from a reference in press (Ting et al. 2016), and 11 in vitro studies

152 (Bergman et al. 2011; Emani et al. 2014; Graziano et al. 2015; Jerwood \& Cohen 2008; Masadeh 153 et al. 2012; Matzneller et al. 2011; Radwan \& Ezzat 2012; Sarabhai et al. 2015; Thangamani et al. 154 2015; Wang et al. 2015; Welsh et al. 2009). No new relevant studies were found after scrutinizing 155 the references of these 16 studies. The relevance of references was reviewed by all the 156 researchers.

157

160

\section{Data extraction}

From the 16 selected studies, the MIC values of statins against various Gram-positive and Gramnegative bacteria were compiled in Table 1 and Table 2 respectively. The dilution methods for (Alshammari 2016), (Bergman et al. 2011), (Quivey 2014), (Welsh et al. 2009), and (Ting et al. 
161 2016) were described in the respective studies. All other studies were tested according to the

162 broth microdilution method stipulated by the Clinical and Laboratory Standards Institute (CLSI),

163 formerly known as National Committee for Clinical Laboratory Standards (NCCLS). The solvent

164 types and solvent concentrations for water insoluble statins (ATV, LVS, PTV, and SMV) were

165 listed wherever available, because different solvents or solvent concentrations may affect the

166 MIC values (Matzneller et al. 2011).

167 Results

168 Antibacterial activity of statins against Gram-positive bacteria

169 Statins exhibited antibacterial activity against a wide spectrum of Gram-positive bacteria

170 including oral microbiota (Staphylococcus epidermidis, Streptococcus anginosus, Streptococcus

171 mutans, Streptococcus pneumoniae, Streptococcus pyogenes, Streptococcus salivarius, and

172 Streptococcus sanguinis, formerly known as Streptococcus sanguis); gut microbiota

173 (Enterococcus faecalis, Enterococcus faecium, Lactobacillus casei, and methicillin-susceptible

174 Staphylococcus aureus [MSSA]); drug-resistant bacteria (vancomycin-resistant Enterococci

175 [VRE], methicillin-resistant coagulase negative S. aureus [MRCoNS], methicillin-resistant $S$.

176 aureus [MRSA], vancomycin-intermediate $S$. aureus [VISA], and vancomycin-resistant $S$. aureus

177 [VRSA]); and environmental bacteria (Bacillus anthracis and Listeria monocytogenes) (Table 1).

178 The antibacterial activity of SMV was found to be generally the most potent (lowest MIC)

179 compared to ATV and RSV, especially against Enterococci $\left(\mathrm{MIC}_{[\mathrm{SMV}]} \approx 32\right.$ to $292 \mu \mathrm{g} / \mathrm{mL}$,

$180 \mathrm{MIC}_{[\mathrm{ATV}]} \approx 83$ to $>250 \mu \mathrm{g} / \mathrm{mL}, \mathrm{MIC}_{[\mathrm{RSV}]} \approx 100$ to $\left.500 \mu \mathrm{g} / \mathrm{mL}\right) ;$ Staphylococci $\left(\mathrm{MIC}_{[\mathrm{SMV}]} \approx 16\right.$ to

$181167 \mu \mathrm{g} / \mathrm{mL}, \mathrm{MIC}_{[\mathrm{ATV}]} \approx 20$ to $>1024 \mu \mathrm{g} / \mathrm{mL}, \mathrm{MIC}_{[\mathrm{RSV}]} \approx 100$ to $>1024 \mu \mathrm{g} / \mathrm{mL}$ ); and Streptococci

$182\left(\mathrm{MIC}_{[\mathrm{SMV}]} \approx 7.8\right.$ to $292 \mu \mathrm{g} / \mathrm{mL}, \mathrm{MIC}_{[\mathrm{ATV}]} \approx 83$ to $229 \mu \mathrm{g} / \mathrm{mL}, \mathrm{MIC}_{[\mathrm{RSV}]} \approx 100$ to $\left.417 \mu \mathrm{g} / \mathrm{mL}\right)$. FLV 
183 exhibited relatively weak antibacterial activity against Staphylococci $\left(\mathrm{MIC}_{[\mathrm{FLV}]}=>200\right.$ to $>1024$

$184 \mu \mathrm{g} / \mathrm{mL})$ and Streptococci $\left(\mathrm{MIC}_{[\mathrm{FLV}]}=>100 \mu \mathrm{g} / \mathrm{mL}\right)$.

185 SMV has been the most widely studied, with researchers examining bacteria which were not 186 tested against other statins such as B. anthracis $\left(\mathrm{MIC}_{[\mathrm{SMV}]}=16 \mu \mathrm{g} / \mathrm{mL}\right)$, L. casei $\left(\mathrm{MIC}_{[\mathrm{SMv}]}=7.8\right.$ $187 \mu \mathrm{g} / \mathrm{mL}$ ), and L. monocytogenes $\left(\mathrm{MIC}_{[\mathrm{SMV}]}=32 \mu \mathrm{g} / \mathrm{mL}\right)$. Few studies have been performed on the 188 other statins, but one study did compare the antibacterial effects of all seven registered statins 189 (ATV, FLV, LVS, PTV, PRV, RSV, and SMV) against MRSA and found that only SMV exhibited 190 antibacterial activity $\left(\mathrm{MIC}_{[\mathrm{SMV}]}=32 \mu \mathrm{g} / \mathrm{mL}\right)$, while all the other six statins did not $(\mathrm{MIC}=>1024$ $191 \mu \mathrm{g} / \mathrm{mL})$ (Thangamani et al. 2015).

\section{Antibacterial activity of statins against Gram-negative bacteria}

From Table 2, statins also displayed varying antibacterial activity against a range of Gramnegative bacteria, including oral microbiota (Aggregatibacter actinomycetemcomitans and Porphyromonas gingivalis); nasopharyngeal microbiota (Haemophilus influenzae and Moraxella catarrhalis); gut microbiota (Citrobacter freundii, Enterobacter aerogenes, Enterobacter cloacae, Escherichia coli, Klebsiella pneumoniae, and Proteus mirabilis); and environmental bacteria (Acinetobacter baumannii, Pseudomonas aeruginosa, and Salmonella Typhimurium). and both were more potent than $\mathrm{RSV}$ against $A$. baumannii $\left(\mathrm{MIC}_{[\mathrm{ATV}]} \approx 16\right.$ to $>128 \mu \mathrm{g} / \mathrm{mL}$, $\mathrm{MIC}_{[\mathrm{SMV}]} \approx 32$ to $>256 \mu \mathrm{g} / \mathrm{mL}, \mathrm{MIC}_{[\mathrm{RSV}]} \approx 300$ to $\left.333 \mu \mathrm{g} / \mathrm{mL}\right)$ and $E$. coli $\left(\mathrm{MIC}_{[\mathrm{ATV}]} \approx 26\right.$ to $>500$ $\mu \mathrm{g} / \mathrm{mL}, \mathrm{MIC}_{[\mathrm{SMV}]} \approx 52$ to $>500 \mu \mathrm{g} / \mathrm{mL}, \mathrm{MIC}_{[\mathrm{RSV}]} \approx 100$ to $\left.>500 \mu \mathrm{g} / \mathrm{mL}\right)$. FLV exerted relatively weak antibacterial activity against $E$. coli $\left(\mathrm{MIC}_{[\mathrm{FLV}]}=500 \mu \mathrm{g} / \mathrm{mL}\right)$ and $P$. aeruginosa $\left(\mathrm{MIC}_{[\mathrm{FLV}]}=\right.$ 
205 against $P$. aeruginosa but did not find any antibacterial activity $(\mathrm{MIC}=>1024 \mu \mathrm{g} / \mathrm{mL})$

206 (Thangamani et al. 2015).

207

208 Variations in MIC results amongst different studies

209 A two-fold difference in MIC, defined as the lowest antimicrobial concentration that completely

210 inhibits microbial growth, is generally accepted (Turnidge \& Paterson 2007). However, greater

211 differences have been reported in some cases amongst various researchers determining the MICs

212 of statins. For example in Table 1 when SMV was tested against a reference American Type

213 Culture Collection (ATCC) MRSA strain (ATCC 43300), the highest $\mathrm{MIC}_{[\mathrm{SMV}]}(\approx 167 \mu \mathrm{g} / \mathrm{mL})$ and

214 lowest $\mathrm{MIC}_{[\mathrm{Smv}]}(\approx 31 \mu \mathrm{g} / \mathrm{mL})$ differed by about five-fold (Graziano et al. 2015; Masadeh et al.

215 2012). Variations in MIC results of a statin against the same bacterial strain between different

216 studies could be attributed to diversity in materials and methods employed, especially if materials

217 were obtained from different manufacturers. Slight deviations in environmental conditions during

218 manufacture, storage, or transport may affect drug or media purity which consequently influences

219 MIC results.

220 Protocols may not specify every minute detail. General instructions for water insoluble solvents

221 allowed investigators to use various types of solvents and solvent concentrations of their choice,

222 which may result in different MIC results (Matzneller et al. 2011). Most of the studies in Tables 1

223 and 2 utilized the CLSI broth microdilution method protocol, which recommends an incubation

224 time of 16 to 20 hours for bacteria such as $S$. aureus, but does not specify if microtiter plates

225 should be subjected to continuous shaking during incubation (Clinical and Laboratory Standards

226 Institute 2012). A window of 4 hours may result in different MIC results between readings taken

227 at 16 hours compared with 20 hours of incubation. Some researchers may choose to subject the

228 plates to shaking during incubation to facilitate exposure of bacteria to the drug or reduce biofilm 
229 formation under static growth conditions. However, continuous shaking during incubation may 230 cause more colonies to grow, affecting MIC results (Liu et al. 2015; Shanholtzer et al. 1984). The 231 CLSI protocol also stipulates that the MIC should be discerned as absence of turbidity with the 233 unaided eye (Clinical and Laboratory Standards Institute 2012). This may lead to subjective results, depending on the ability of individuals to detect minute disparities in turbidity.

In view of the multiple factors hampering reproduction of results, it may be more meaningful to compare absolute quantitative results (e.g. MIC) within studies performed by the same researchers, whilst qualitative results or trends (e.g. spectrum of antibacterial efficacy) could be analyzed between studies by different researchers.

\section{Discussion}

The positive factors which promote the use of statins as novel adjuvant antibiotics for infections (statins as AMR breakers), the negative factors whereby acquired antibacterial resistance against statins could culminate in AMR (statins as AMR makers), and knowledge gaps are summarized in Figure 2 and elaborated as follows.

\section{AMR breaker: Intrinsic antibacterial activity}

The MIC values in Tables 1 and 2 provide in vitro evidence of individual statins' inherent antibacterial effects against various Gram-positive and Gram-negative bacteria gleaned from literature thus far. SMV has been the most widely studied and demonstrated antibacterial activity against different types of microbiota (oral, gut, and nasopharyngeal) and environmental bacteria (Tables 1 and 2). SMV also exerted antibacterial effects against Gram-positive drug resistant bacteria such as MRCoNS, MRSA, VISA, VRE, and VRSA (Table 1). Therefore, SMV may 
250 prove to be an effective antibiotic adjuvant, but in vivo studies are required to confirm its clinical 251 antibacterial efficacy.

\section{2}

253

254

255

\section{Knowledge gap: Contribution of statins as AMR makers via selective pressures or co-selection}

Despite evidence of statins' intrinsic antibacterial effects, the life span of statins as novel adjuvant antibiotics serving as AMR breakers may be limited due to the widespread use of statins for nonantibiotic purposes (cardiovascular protection). Such extensive usage exposes susceptible bacteria in humans and the environment to varying concentrations of statins, favoring selective pressures for antibacterial resistance. The possible scenarios and repercussions of exposing susceptible bacterial strains to low (up to several hundred times below MIC) and high (within eight to ten times above MIC) statin concentrations are discussed later in this review. Emergence of AMR due to selective pressures are difficult to predict due to variable influences present in humans, animals, and the environment (Hughes \& Andersson 2017). However, it is certain that the development of AMR occurs naturally in bacteria when exposed to antimicrobials (Blair et al. 2015).

Antibiotics, biocides, metals, and non-antibiotic chemicals with antibacterial properties may also induce resistance to multiple antibiotic classes via co-selection (Singer et al. 2016; Wales \& Davies 2015). Bacteria may develop multidrug resistance via inheriting genes conferring various resistance mechanisms such as reduced cell permeability to antibiotics, increased efflux of antibiotics, modification of antibiotic targets, or direct inactivation of antibiotics (Blair et al. 2015). Co-selection occurs via cross-resistance (selection of a gene conferring multiple resistance mechanisms) or co-resistance (selection of physically linked genes which collectively confer various resistance mechanisms) (Singer et al. 2016; Wales \& Davies 2015). This is of particular 
273

274 pressures (Wales \& Davies 2015).

275 To date, there is evidence that exposure of bacteria to non-antibiotic chemicals with antibacterial

276 properties (chlorite and iodoacetic acid) may induce AMR (Li et al. 2016). Hence, there is a

277 possibility of statins, as non-antibiotic chemicals with antibacterial properties, to similarly

278 contribute as AMR makers, although there is currently little known evidence of such statin

279 associations.

280

281

It was found that ATV unlikely contributed to efflux-mediated resistance in multidrug-resistant

Gram-negative bacteria (Laudy et al. 2017). As a result, statins probably contribute as AMR makers via other resistance mechanisms. More studies on statins' mechanism of antibacterial resistance, as well as the mechanism of antibacterial activity, are required to determine and thus control the extent of statins' plausible role as AMR makers.

\section{Knowledge gap: Mechanism of statins' antibacterial action}

\section{(Fungal origin unlikely correlates with statins'antibacterial activity)}

SMV, LVS, and PRV have been classified as Type 1 statins (derived from fungal origins and have similar chemical structures) while ATV, FLV, PTV, and RSV have been classified as Type 2 statins (synthetic compounds with chemical groups which bind more tightly with HMG-CoA reductase), as shown in Figure 3 (Gazzerro et al. 2012). Although SMV, LVS, and PRV have similar chemical structures, SMV exhibited antibacterial properties against S. aureus but LVS and PRV do not, despite all three being of fungal origin (Thangamani et al. 2015). Moreover, ATV and RSV are synthetic compounds and not of fungal origin, but both exhibited some antibacterial 
294 activity (Masadeh et al. 2012). As such, statins' fungal origin unlikely correlates with their 295 antibacterial activity.

296 Knowledge gap: Mechanism of statins'antibacterial action

297 (Inhibition of human or bacterial HMG-CoA reductase unlikely correlates with statins' 298 antibacterial activity)

299 When administered in humans, all statins inhibit HMG-CoA reductase in the mevalonate pathway 300 to lower cholesterol synthesis. However, not all statins exhibit antibacterial activity (Tables 1 and 301 2). The presence of the dihydroxy acid moiety is required to competitively inhibit the catalytic 302 function of HMG-CoA reductase and reduce cholesterol synthesis (Harrold 2013). Statins with 303 lactone groups (SMV and LVS) are prodrugs which must be metabolized to the active dihydroxy 304 acid moiety before they may inhibit HMG-CoA reductase (Harrold 2013). Yet SMV, being unable 305 to directly inhibit HMG-CoA reductase, exhibits antibacterial activity against MRSA whilst PRV 306 and PTV, being direct HMG-CoA reductase inhibitors, do not exhibit antibacterial activity 307 (Thangamani et al. 2015).

308 In addition, the degree of HMG-CoA reductase inhibition corresponds directly with the 309 cholesterol-lowering capabilities of statins (Liao \& Laufs 2005), but it does not seem 310 commensurate with antibacterial potency. The cholesterol-lowering potency of statins has been 311 established in the following order: PTV (most potent) $>$ RSV $>$ ATV $>$ SMV $>$ PRV $>$ LVS $>$ 312 FLV (least potent) (Armitage 2007). RSV is a more potent cholesterol-lowering drug compared to 313 SMV, but SMV demonstrated greater antibacterial activity (Tables 1 and 2), indicating that 314 antibacterial activity may not correlate with the inhibition of human HMG-CoA reductase. 
315 Humans and some Gram-positive bacteria such as S. aureus synthesize essential isoprenoids via

316 the mevalonate pathway (Heuston et al. 2012), whereby HMG-CoA reductase is a catalyst in the 317 rate determining step. However, humans and bacteria have different overall HMG-CoA reductase

318 structures. When administered in humans, statins preferentially bind to human HMG-CoA

319 reductase (Class I) instead of bacterial HMG-CoA reductase (Class II) because the affinity of

320 statins is about 10,000 times stronger for human HMG-CoA reductase (Friesen \& Rodwell 2004).

321 Hence, statins are not likely to exert antibacterial effects via inhibition of bacterial HMG-CoA

322 reductase.

323 Furthermore, many types of Gram-negative bacteria, for example E. coli and P. aeruginosa,

324 synthesize isoprenoids via an alternative metabolic pathway (2C-methyl-D-erythritol 4-phosphate

$325[\mathrm{MEP}]$ ), which do not require HMG-CoA reductase (Heuston et al. 2012). Yet, certain statins

326 (ATV, RSV, and SMV) exert some antibacterial activity against E. coli, P. aeruginosa, and

327 various Gram-negative bacteria (Table 2), likely via a mechanism independent of bacterial HMG-

328 CoA reductase inhibition.

\section{Knowledge gap: Mechanism of statins' antibacterial action}

\section{(Postulated mechanism derived from structure-activity relationship analysis)}

The mechanism of action for statins' antibacterial effects has yet to be elucidated. The nature of antibacterial activity for SMV against Gram-positive bacteria was found to be bacteriostatic at drug concentrations that equal MIC (Thangamani et al. 2015), but bactericidal at concentrations four times greater than MIC (Graziano et al. 2015). Suggested mechanisms for statins' antibacterial effects include the pleiotropic effects of statins repressing cell growth (Masadeh et al. 2012), or the hydrophobic nature of SMV disrupting bacterial membrane in a "soap-like" manner (Bergman et al. 2011), or the reduction of biofilm viability and production (Graziano et 
338 al. 2015). It was also hypothesized that by lowering host cholesterol levels, statins may reduce

339 the production of a protective membrane-stabilising metabolite in the mevalonate pathway, 340 resulting in bacterial cell toxicity (Haeri et al. 2015).

341 By comparing the chemical structures of statins with known antibacterial activity against statins

342 without antibacterial activity, the presence of two methyl groups arranged in a tetrahedral

343 molecular geometry were identified as important moieties responsible for statins' antibacterial

344 activity (Figure 3). We postulate that statins may interfere with bacterial cell regulatory functions

345 through non-polar interactions of statins' methyl groups with alanine residues present in Gram-

346 positive bacterial surface structures such as wall teichoic acids and lipoteichoic acids; hydrogen

347 bond disruptions within Gram-negative bacterial surface lipopolysaccharide structures; and/or via

348 hydrogen bonds and van der Waals forces with various other Gram-positive and Gram-negative

349 bacterial surface proteins to exert bacteriostatic effects (or bactericidal effects at higher statin

350 concentrations). The binding interactions may be similar to the manner by which antimicrobial

351 peptides accumulate at bacterial surfaces (Malanovic \& Lohner 2016).

352 In Figure 3, carbon atoms attached to two methyl groups arranged in a tetrahedral molecular

353 geometry appeared to be common amongst the chemical structures of statins with antibacterial

354 activity (SMV, ATV, FLV, and RSV). In particular, the structures of SMV and LVS are almost

355 identical, except that SMV contains a carbon with two methyl groups in the ester side chain

356 whereas LVS contains a carbon with only one methyl group. Since SMV has antibacterial effects

357 against MRSA while LVS does not (Thangamani et al. 2015), this suggests the importance of the

358 additional methyl moiety in the mechanism of action. 
359 Bacteria have a high affinity for attaching to environmental surfaces, and one of the attachment

360 methods involves non-polar interactions between a hydrophobic methyl group and a hydrophobic

361 side group of an alanine residue (Boland et al. 2000). Repeating alanine residues are found in

362 wall teichoic acids and lipoteichoic acids (Lebeer et al. 2010), which are important anionic

363 polymers protecting bacteria against noxious environmental stress, assisting in bacteria

364 colonisation, infection, and immune evasion (Brown et al. 2013; Xia et al. 2010). The two methyl

365 groups from statins may be in the exact conformation (tetrahedral geometry) to directly bind with

366 alanine residues of wall teichoic acids and lipoteichoic acids protruding from the peptidoglycan

367 cell wall in Gram-positive bacteria (Silhavy et al. 2010), causing structural distortions which may

368 interfere with cell division (Hanson \& Neely 2012). In further support, an omission or decline in

369 alanine residues of wall teichoic acids reduces biofilm adhesion and formation, as well as

370 increases bacterial susceptibility to antibiotics, cationic antimicrobial peptides, phagocytes, and

371 neutrophils (Brown et al. 2013).

372 There are also other surface proteins responsible for various roles in S. aureus such as adhering to

373 and invading host cells, evading host immune responses, and formation of biofilms (Foster et al.

374 2014). Statins are able to change their conformation and bind extensively to proteins $(\geq 88 \%$

375 protein binding, except for PRV which exhibits about $43 \%$ to $54 \%$ protein binding) through van

376 der Waals forces and hydrogen bonds (Gazzerro et al. 2012; Shi et al. 2016). Therefore, the

377 binding of statins to bacterial surface proteins may influence various metabolic pathways to

378 reduce bacteria proliferation and virulence. This may account for the lack of antibacterial activity

379 of PRV, which possessed significantly lower protein binding properties. Incidentally,

380 amitriptyline (antidepressant), chlorpromazine (antipsychotic), propranolol (antihypertensive),

381 and tamoxifen (anticancer) are other non-antibiotic drugs from different pharmacological classes

382 which are highly protein bound (>90\%), possess atoms attached to two methyl groups with a 
383 tetrahedral or a similar trigonal pyramidal molecular geometry, and also exhibit antibacterial

384 activity against S. aureus (Figure 3) (Kruszewska et al. 2006; Kruszewska et al. 2010; Mandal et 385 al. 2010).

386 The postulated mechanism of statins binding to bacterial cell surface structures and/or surface 387 proteins also aligned with the results of two studies showing $\mathrm{MIC}_{\text {[statin] }}(\mathrm{MRSA})>\mathrm{MIC}_{\text {[statin] }}$ 388 (MSSA) (Jerwood \& Cohen 2008; Masadeh et al. 2012). MRSA cocci are smaller than MSSA 389 cocci and have a statistically higher cell surface to plasma volume ratio (Kocsis et al. 2010). As 390 such, more statin drug may be required to bind to the corresponding higher number of surface 391 attachments or proteins in MRSA, compared to MSSA cocci.

392 Gram-negative bacteria cells contain various exposed structures such as lipopolysaccharides and 393 surface proteins protruding from the outer cell membrane (Lebeer et al. 2010).

394 Lipopolysaccharide structures serve as a protective barrier and regulator of solutes (Rosenfeld \& 395 Shai 2006; Ruiz et al. 2009). Disruption of the stabilized hydrogen bond interactions within 396 lateral lipopolysaccharide structures results in a possible breach in the barrier function (Ruiz et al. 397 2009). Statins may bind to immobilized artificial membranes (which mimic the fluid 398 phospholipid bilayer of cell membranes) via van der Waals forces and hydrogen bonds (Sarr et al. 399 2008). Hence some of the antibacterial effects exerted by statins on Gram-negative bacteria may 400 be a result of statins' hydrogen bond forces disrupting the lipopolysaccharide structure, and/or 401 binding to the cell membrane surface proteins.

402 It was hypothesized that the inhibition of statins via the mevalonate pathway reduces a protective 403 metabolite because the addition of cholesterol to Gram-positive (S. aureus and E. faecalis) and 404 Gram-negative (E. coli and P. aeruginosa) bacteria decreased the antibacterial effects of statins 
405 (Haeri et al. 2015). The decreased antibacterial effect may be in part due to an increase in

406 bacterial load as the in vitro addition of cholesterol has been shown to increase $S$. aureus growth

407 (Shine et al. 1993). However, bacteria such as S. aureus and E. coli are able to incorporate

408 exogenous cholesterol into their cell membranes (Eaton et al. 1981; Shine et al. 1993), increasing

409 rigidity of the membranes and likely reduce disruptions of cell surface structures (Brender et al.

410 2012). Thus, statins may be unable to bind to rigid membranes in the required conformation, or

411 are unable to distort cell surface structures, further supporting this review's postulated mechanism

412 of statins' antibacterial activity.

413 More studies are required to accurately determine statins' mechanism of antibacterial effects

414 because if the antibacterial mechanism directly threatens bacteria survival, resistance develops

415 more rapidly (Park \& Liu 2012). Even if statins are not repurposed as novel adjuvant antibiotics,

416 their current extensive use for cardiovascular protection may still significantly influence

417 susceptible bacteria.

\section{AMR breaker: Synergistic antibiotic effects}

419 The combination of antibiotics with drugs that possess direct antibacterial properties or

420 synergistic activity may impede AMR (Brown 2015), especially when local delivery of drugs

421 with different mechanisms of action are utilized (Brooks \& Brooks 2014). SMV exerted

422 synergistic antibacterial effects against $S$. aureus clinical isolates with the topical antibiotics

423 daptomycin, fusidic acid, mupirocin, and retapamulin (Thangamani et al. 2015). However, no

424 synergism was found when SMV was combined with vancomycin against $S$. aureus (Graziano et

425 al. 2015); when ATV, FLV, LVS, PRV, and SMV were each combined with amikacin, imipenem,

426 or minocycline against $A$. baumannii (Farmer et al. 2013); or when ATV and FLV were each 
427 combined with ciprofloxacin, cefepime, or piperacillin-tazobactam against E. coli, $K$.

428 pneumoniae, and P. aeruginosa respectively (Farmer et al. 2013).

\section{AMR breaker: Attenuated virulence factors}

430 Virulence factors enable bacteria to harm the host (via adhesion, invasion, colonisation, and toxin

431 secretion); or protect bacteria from the host's immune defences (via secretion of immune

432 response inhibitors, formation of capsules, and biofilms) (Wu et al. 2008). Instead of directly

433 threatening bacterial survival with antibiotics that affect essential bacterial genes, it has been

434 suggested that non-threatening approaches such as disarming bacteria by attenuating virulence

435 factors may help reduce AMR (Park \& Liu 2012).

436 Through the inhibition of Rho signaling activities and reduced cholesterol production, statins

437 have been observed to attenuate virulence factors. Some examples include reducing bacteria

438 motility and attachment, suppressing production of toxins (Panton-Valentine leucocidin and

439 alpha-hemolysin), directly reducing bacterial translocation and invasion, or protecting against

440 bacterial invasion indirectly via inhibiting lipid raft formation (Hennessy et al. 2016). Statins may

441 also prevent biofilm formation, limit biofilm production, and reduce cell viability in matured

442 biofilms (Graziano et al. 2015).

AMR breaker: Enhanced host immunity

444 Stimulation of the host's defence mechanisms to help resolve infections may potentially break 445 AMR (Brown 2015; Park \& Liu 2012). Statins have been shown to directly improve the host's

446 immune defence in humans as well as in animal models (Chow et al. 2010; Frostegard et al.

447 2016; Parihar et al. 2016; Walton et al. 2016; Yang et al. 2014). In humans, ATV and SMV may

448 inhibit pro-inflammatory $\mathrm{T}$ cells and induce anti-inflammatory $\mathrm{T}$ regulatory cells via a novel 
449 method involving the downregulation of microRNA let-7c (Frostegard et al. 2016). Clinical

450 studies revealed that SMV enhanced neutrophil function and improved chronic obstructive

451 pulmonary diseases (Walton et al. 2016). In addition, women taking statins were less likely to be

452 hospitalized due to the activation of lung macrophage nitric oxide synthase-3, which increases

453 bacterial killing, clearance, and host survival in pneumonia (Yang et al. 2014). In animal models,

454 SMV was found to protect mice against Leishmania major via augmented phagosome maturation

455 and increased levels of oxidative hydrogen peroxide (Parihar et al. 2016).

456 However, statins may also unpredictably influence host immunity via factors such as NET

457 production, pleiotropic effects during sepsis, and binding as agonists to nuclear receptors as

458 discussed below. More studies are required in these ambiguous areas to determine the overall

459 effects of statins on host immunity and consequently, whether statins potentially break or

460 contribute to AMR.

461 Knowledge gap: Neutrophil extracellular trap production

462 FLV, LVS, and SMV have been shown to produce NETs, which are complexes of nuclear DNA,

463 histones, antimicrobial peptides, and proteases capable of trapping and killing a wide spectrum of

464 microorganisms (Chow et al. 2010). However, there is also conflicting evidence that statins do

465 not affect NET production (Sorensen \& Borregaard 2016). Further studies may be required to

466 confirm the effect of statins on NETs, as well as whether the NET complexes are in sufficient

467 concentrations to be antibacterial (Sorensen \& Borregaard 2016).

\section{Knowledge gap: Pleiotropic effects in sepsis}

469 Statins may potentially benefit sepsis by reducing inflammation via intracellular signaling

470 (Terblanche et al. 2007), lowering catecholamine levels (Millar \& Floras 2014), or reducing Toll- 
471 like receptor activation by pathogen associated molecular patterns (PAMPs) (Wittebole et al.

472 2010). Statins also possess antiangiogenic (at high doses) and antioxidant effects (Gazzerro et al.

473 2012), which may prevent the progression of severe sepsis (Vera et al. 2015). However, sepsis is

474 a complex condition and there have been conflicting results of statins' effects from meta-analysis

475 studies (Bjorkhem-Bergman et al. 2010; Deshpande et al. 2015; Janda et al. 2010; Quinn et al.

476 2016).

477 During early sepsis, high levels of catecholamines and PAMPs such as lipopolysaccharides and

478 lipoteichoic acids cause an initial pro-inflammatory response (Murphy et al. 2004; Rittirsch et al. 479 2008). An anti-inflammatory response may be initiated concurrent to the initial inflammation and 480 in some cases, secondary infections may cause a secondary pro-inflammatory response (Murphy 481 et al. 2004). As sepsis continues, pathogenic bacteria may induce vagal stimulation to decrease 482 catecholamines and suppress the host's immune system (Weinstein et al. 2015). There are also 483 many other pro-inflammatory factors (protein catabolism, cachexia, and persistent inflammation) 484 and anti-inflammatory factors (defects in adaptive immunity) that occur slightly later after the 485 onset of sepsis (Binkowska et al. 2015). These variables make it difficult to appropriately 486 administer statins to reduce inflammation or catecholamine levels because it is uncertain if the 487 host is in an overall state of immunostimulation or immunosuppression at any one point in time 488 during sepsis.

489 Furthermore, the possibility of using statins in infections is further complicated by the potency of statins, whereby different types and doses of statins resulted in different outcomes (Ou et al. 2014). At low doses, statins exhibit proangiogenic effects (Gazzerro et al. 2012), which may be

492 detrimental in severe sepsis (Vera et al. 2015). Hence varying administration times, different 493 types or doses of statin could have caused the conflicting results in meta-analysis studies. 


\section{Knowledge gap: Nuclear receptor agonists}

495 Statins may indirectly influence the human immune system by binding as agonists to various 496 nuclear receptors, namely farnesoid X receptors (FXRs), glucocorticoid receptors (GCRs), 497 pregnane X receptors (PXRs), and vitamin D receptors (VDRs) (Howe et al. 2011; Marshall

498 2006). Statins may also indirectly induce peroxisome proliferator-activated receptor gamma 499 (PPAR $\gamma$ ) activity (Paumelle \& Staels 2007). The activation of FXRs and VDRs induce 500 antimicrobial peptide gene expression (Schaap et al. 2014), whilst activation of GCRs, PXRs, and 501 PPAR $\gamma$ result in anti-inflammatory effects (Kadmiel \& Cidlowski 2013; Paumelle \& Staels 2007; 502 Schaap et al. 2014).

503 Although statins may bind as agonists to nuclear receptors, a direct increase in nuclear receptor 504 activity may not be apparent because by inhibiting the mevalonate pathway, statins reduce the 505 production of several nuclear receptor agonists such as cholesterol (precursor of glucocorticoids 506 which are GCR and PXR agonists), bile acids (FXR agonist), and vitamin D (VDR agonist) (Liao 507 2005). Moreover, nuclear receptors may also influence the production of other receptor agonists 508 (e.g. activation of PXR reduces bile acid production) (Schaap et al. 2014), and nuclear receptor 509 agonists are not receptor specific (e.g. bile acids are agonists at both FXRs and VDRs; vitamin D 510 is an agonist at GCRs, PXRs, and VDRs) (Gombart 2009; Mangin et al. 2014; Marshall 2006).

511 Some nuclear receptor agonists which boost the human immune system may ironically influence

512 bacterial morphology directly to cause antibiotic tolerance (e.g. bile acids may activate FXRs and 513 VDRs to stimulate antimicrobial peptide production, but bile acids also induce biofilm changes 514 resulting in antibiotic resistant chronic infections) (Reen et al. 2016; Schaap et al. 2014). In view 
515 of the numerous variables, of which some are antagonistic, it is difficult to anticipate the net

516 effect of statins on the immune system via nuclear receptor activity.

517

518 AMR breaker: Improved wound healing

519 Uncomplicated skin and wound infections are amongst one of the highest causes for outpatient 520 antibiotic usage (Hurley et al. 2013). As a result, inappropriate or prolonged antibiotic use may 521 contribute to AMR. Antibacterial agents aiding in wound healing should serve to reduce bacterial 522 infection and improve healing time, thus limiting exposure time to antibiotics. Statins are 523 theoretically ideal for wound healing because they may act as PXR agonists to enhance wound 524 healing in intestinal epithelial cells, inhibit FPP (an activator of GCR which impedes wound

525 healing), reduce inflammation, regulate epithelial homeostasis, promote angiogenesis at low 526 doses, reduce oxidative stress, increase vascular endothelial growth factors, and increase levels of 527 nitric oxide (Bu et al. 2011; Calanni et al. 2014; Elewa et al. 2010; Farsaei et al. 2012;

528 Fitzmaurice et al. 2014; Vukelic et al. 2010). The effects of oral statins (ATV, SMV, LVS, PRV, 529 and RSV) and topical statins (ATV, SMV, and LVS) have been examined and it was concluded 530 that there was sufficient evidence to warrant clinical trials assessing the potential efficacy of 531 statins in postoperative wound healing (Fitzmaurice et al. 2014).

\section{AMR maker: Dysbiosis of gut microbiota}

533 Antimicrobials disrupting the gut microbiota may cause AMR and potentially create a store of 534 AMR genes in the gut microbiota, resulting in recalcitrant infections (Francino 2016). Statins 535 have been shown to reduce gut microbiota diversity in humans (Zhernakova et al. 2016), but the 536 mechanism of dysbiosis of the human gut microbiota has not been elucidated. A recent animal 537 study has shown that statin-induced bile acid alterations resulted in mouse gut dysbiosis via a 538 PXR-dependent mechanism (Caparros-Martin et al. 2017). Our review provides plausible 
539 evidence that statins may additionally disrupt the human gut microbiota via a direct antimicrobial 540 effect.

541 From Tables 1 and 2, Gram-positive (E. faecalis, E. faecium, L. casei, and S. aureus) and Gram542 negative (C. freundii, E. aerogenes, E. cloacae, E. coli, K. pneumoniae, and P. mirabilis) gut 543 microbiota were susceptible to various statins, whereby $\mathrm{MIC}_{[\mathrm{SMV}]} \approx 8$ to $>500 \mu \mathrm{g} / \mathrm{mL}$ (Matzneller 544 et al. 2011; Ting et al. 2016), $\mathrm{MIC}_{[\mathrm{ATV}]} \approx 16$ to $>1024 \mu \mathrm{g} / \mathrm{mL}$ (Masadeh et al. 2012; Thangamani et 545 al. 2015), $\mathrm{MIC}_{[\mathrm{RSV}]} \approx 100$ to $>1024 \mu \mathrm{g} / \mathrm{mL}$ (Thangamani et al. 2015; Welsh et al. 2009), and $546 \quad \mathrm{MIC}_{[\mathrm{FLV}]}=>200$ to $>1024 \mu \mathrm{g} / \mathrm{mL}$ (Jerwood \& Cohen 2008; Thangamani et al. 2015).

547 The licensed oral daily dose range of statins for cholesterol-lowering purposes are SMV $=\mathrm{ATV}=$ $54810 \mathrm{mg}$ to $80 \mathrm{mg}(10,000 \mu \mathrm{g}$ to $80,000 \mu \mathrm{g}), \mathrm{FLV}=40 \mathrm{mg}$ to $80 \mathrm{mg}(40,000 \mu \mathrm{g}$ to $80,000 \mu \mathrm{g})$, and $549 \mathrm{RSV}=5 \mathrm{mg}$ to $40 \mathrm{mg}(5,000 \mu \mathrm{g}$ to $40,000 \mu \mathrm{g})$ (Armitage 2007). The laboratory conditions (35 $550{ }^{\circ} \mathrm{C}$ and $\mathrm{pH} 7.2$ to 7.4 ) at which MIC values were determined are attainable when gut microbiota 551 are exposed to statins along the gastrointestinal tract $\left(37^{\circ} \mathrm{C}\right.$ body temperature and $\mathrm{pH} 7.2$ to 7.4 552 along various parts of the small intestines) (Clinical and Laboratory Standards Institute 2012; 553 Khutoryanskiy 2015). Although gut concentrations of orally administered parent statin drugs are 554 reduced via absorption, distribution, and metabolism as they move along the gastrointestinal tract, 555 the reduction in concentrations are limited by enterohepatic circulation, and statins are eventually 556 excreted mainly in the feces (SMV $\approx 60 \%, \mathrm{ATV}>98 \%, \mathrm{FLV} \approx 93 \%$, and $\mathrm{RSV} \approx 90 \%$ )

557 (McFarland et al. 2014; Reinoso et al. 2002). As such, statin concentrations along the 558 gastrointestinal tract are likely sufficient to kill gut microbiota. Even if gut statin concentrations 559 fall below MIC, prolonged gut microbiota exposure to drug concentrations up to several hundred 560 times lower than MIC may still result in selective pressures for resistance (Andersson \& Hughes $5612011)$. 
562

563

564

565

566

567

568

569

570

571

572

573

574

575

576

577

578

579

580

581

582

583

AMR maker: Statin plasma concentrations in bacteremic patients being much lower than MIC

Oral doses of statins may be high enough to exert antimicrobial effects in the gut, but the peak statin plasma concentrations have been found to be much lower $(\mathrm{SMV} \approx 0.0209 \mu \mathrm{g} / \mathrm{mL}, \mathrm{ATV} \approx$

$0.01 \mu \mathrm{g} / \mathrm{mL}, \mathrm{RSV} \approx 0.037 \mu \mathrm{g} / \mathrm{mL}$, and $\mathrm{FLV} \approx 0.24 \mu \mathrm{g} / \mathrm{mL}$ ) due to low bioavailability and protein binding (Jerwood \& Cohen 2008; Kantola et al. 2000; Welsh et al. 2009). Hence, statins are unlikely to exert significant systemic antimicrobial effects since the peak plasma concentrations range from hundred to thousand times lower than the MIC. Of greater concern however, is the risk of exposing bacteremic patients to such low systemic antimicrobial concentrations, which may result in selective pressures for resistance (Andersson \& Hughes 2011).

\section{AMR maker: Environmental impact due to extensive use of stains}

The present usage of statins (ATV, RSV, and SMV) has resulted in residual levels ( $\mu \mathrm{g} / \mathrm{mL}$ to $\mathrm{pg} / \mathrm{mL}$ ) persisting in sewage for at least a few weeks (Lee et al. 2009; Ottmar et al. 2012). Since the exposure of bacteria to antibiotic concentrations several hundred times below MIC (in the range of $\mu \mathrm{g} / \mathrm{mL}$ to $\mathrm{pg} / \mathrm{mL}$ ) poses a risk of bacterial resistance (Andersson \& Hughes 2011), this lingering exposure of bacteria in the sewage system to current statin concentrations may thus contribute to selective pressures for resistance.

\section{Conclusion}

The potential roles of statins as AMR breakers, AMR makers, and knowledge gaps in the statinbacteria-human-environment continuum have been summarized in Figure 2. Literature has shown that SMV, ATV, RSV, and FLV exert varying antibacterial effects on Gram-positive and Gramnegative bacteria (Tables 1 and 2), especially SMV (against most of the Gram-positive bacteria tested) and ATV (against most of the Gram-negative bacteria tested). However, SMV currently 
584 appears to be the best candidate as a novel adjuvant antibiotic because it has been the most 585 widely studied statin and demonstrated direct in vitro antibacterial activity against various types 586 of microbiota (oral, gut, and nasopharyngeal), drug-resistant bacteria, and environmental bacteria. 587 Based on the structure-activity relationship analysis of statins' chemical structures, it is plausible 588 that statins' mechanism of antibacterial activity involves the interference of bacterial cell 589 regulatory functions via binding to bacterial cell surface structures such as wall teichoic acids and 590 lipoteichoic acids (for Gram-postive bacteria), lipopolysaccharides (for Gram-negative bacteria), 591 and/or bacterial surface proteins (for both Gram-positive and Gram-negative bacteria).

592 Current evidence better supports statins as AMR breakers by working synergistically with 593 existing topical antibiotics, attenuating virulence factors, boosting human immunity, or aiding in 594 wound healing. However, the paucity of data directly associating statins to AMR should not 595 exclude statins' role as plausible AMR makers. The widespread use of statins for non-antibiotic 596 (cardioprotective) purposes may favor selective pressures or co-selection for resistance via 597 dysbiosis of the human gut microbiota, sublethal plasma concentrations in bacteremic patients, 598 and persistence in the environment, all of which could culminate in AMR.

599 Perhaps the most urgent knowledge gap to address is determining the mechanism of statins' 600 antibacterial activity. If the antibacterial mechanism involves disarming bacteria instead of 601 directly threatening bacterial survival, AMR is not likely to develop rapidly (Park \& Liu 2012), 602 and statins may still play an effective role as AMR breakers. However, if the antibacterial 603 mechanism directly threatens bacterial survival, AMR is likely to develop rapidly. If so, statins' 604 role as AMR breakers will likely be limited, and may paradoxically function as AMR makers 605 instead. 


\section{Acknowledgements}

607 The authors wish to thank all their friends and colleagues at the Curtin Health Innovation

608 Research Institute (CHIRI) Biosciences Research Precinct Core Facility (Curtin University),

609 especially Dr Joshua Ramsay, for making this work possible.

\section{References}

611 Alshammari A. 2016. In vitro effect of statins on Streptococcus mutans, Streptococcus sanguis, and Streptococcus salivarius Master of Science. Temple University, Philadelphia, United States of America.

Andersson DI, and Hughes D. 2011. Persistence of antibiotic resistance in bacterial populations. FEMS Microbiol Rev 35:901-911. 10.1111/j.1574-6976.2011.00289.x

Andersson DI, and Hughes D. 2014. Microbiological effects of sublethal levels of antibiotics. Nat Rev Microbiol 12:465-478. 10.1038/nrmicro3270

Armitage J. 2007. The safety of statins in clinical practice. Lancet 370:1781-1790.

$$
10.1016 / \mathrm{S} 0140-6736(07) 60716-8
$$

Bergman P, Linde C, Putsep K, Pohanka A, Normark S, Henriques-Normark B, Andersson J, and Bjorkhem-Bergman L. 2011. Studies on the antibacterial effects of statins--in vitro and in vivo. PLoS One 6:e24394. 10.1371/journal.pone.0024394

Binkowska AM, Michalak G, and Slotwinski R. 2015. Current views on the mechanisms of immune responses to trauma and infection. Cent Eur J Immunol 40:206-216. 10.5114/ceji.2015.52835

Bjorkhem-Bergman L, Bergman P, Andersson J, and Lindh JD. 2010. Statin treatment and mortality in bacterial infections--a systematic review and meta-analysis. PLoS One 5:e10702. 10.1371/journal.pone.0010702 
629 Bjorkhem-Bergman L, Lindh JD, and Bergman P. 2011. What is a relevant statin concentration in 630 cell experiments claiming pleiotropic effects? Br J Clin Pharmacol 72:164-165. 10.1111/j.1365-2125.2011.03907.x

Blaha MJ, and Martin SS. 2013. How do statins work?: changing paradigms with implications for statin allocation. J Am Coll Cardiol 62:2392-2394. 10.1016/j.jacc.2013.08.1626

Blair JM, Webber MA, Baylay AJ, Ogbolu DO, and Piddock LJ. 2015. Molecular mechanisms of antibiotic resistance. Nat Rev Microbiol 13:42-51. 10.1038/nrmicro3380

Boland T, Latour RA, and Stutzenberger FJ. 2000. Molecular Basis of Bacterial Adhesion. In: Yuehuei HA, and Friedman RJ, eds. Handbook of Bacterial Adhesion: Principles, Methods, and Applications. 2000 ed. Totowa, New Jersey: Humana Press Inc, 29-41.

Brender JR, McHenry AJ, and Ramamoorthy A. 2012. Does cholesterol play a role in the bacterial selectivity of antimicrobial peptides? Front Immunol 3:195. Drug Deliv Rev 78:14-27. 10.1016/j.addr.2014.10.027 void? Nat Rev Drug Discov 14:821-832. 10.1038/nrd4675 10.3389/fimmu.2012.00195

Brooks BD, and Brooks AE. 2014. Therapeutic strategies to combat antibiotic resistance. Adv

Bu DX, Griffin G, and Lichtman AH. 2011. Mechanisms for the anti-inflammatory effects of Annu Rev Microbiol 67:313-336. 10.1146/annurev-micro-092412-155620 statins. Curr Opin Lipidol 22:165-170. 10.1097/MOL.0b013e3283453e41

Calanni F, Renzulli C, Barbanti M, and Viscomi GC. 2014. Rifaximin: beyond the traditional antibiotic activity. J Antibiot (Tokyo) 67:667-670. 10.1038/ja.2014.106 
654

655

656

657

658

659

660

661

662

663

664

665

666

667

668

669

670

671

672

673

674

675

676

677

678

resistance. Enferm Infecc Microbiol Clin 31 Suppl 4:3-11. 10.1016/S0213-

005X(13)70126-5

Caparros-Martin JA, Lareu RR, Ramsay JP, Peplies J, Jerry Reen F, Headlam HA, Ward NC, Croft KD, Newsholme P, Hughes JD, and O'Gara F. 2017. Statin therapy causes gut dysbiosis in mice through a PXR-dependent mechanism. Microbiome 5:95.

10.1186/s40168-017-0312-4

Chow OA, von Kockritz-Blickwede M, Bright AT, Hensler ME, Zinkernagel AS, Cogen AL, Gallo RL, Monestier M, Wang Y, Glass CK, and Nizet V. 2010. Statins enhance formation of phagocyte extracellular traps. Cell Host Microbe 8:445-454.

10.1016/j.chom.2010.10.005

Clinical and Laboratory Standards Institute. 2012. Methods for Dilution Antimicrobial Susceptibility Tests for Bacteria That Grow Aerobically; Approved Standard-Ninth Edition. CLSI document M07-A9. Wayne, Pennsylvania, USA: Clinical and Laboratory Standards Institute.

Coban AY, Tekeli HO, Guney AK, and Durupinar B. 2010. [Investigation of the in vitro antibacterial effects of statins]. Mikrobiyol Bul 44:161-163.

Collins R, Reith C, Emberson J, Armitage J, Baigent C, Blackwell L, Blumenthal R, Danesh J, Smith GD, DeMets D, Evans S, Law M, MacMahon S, Martin S, Neal B, Poulter N, Preiss D, Ridker P, Roberts I, Rodgers A, Sandercock P, Schulz K, Sever P, Simes J, Smeeth L, Wald N, Yusuf S, and Peto R. 2016. Interpretation of the evidence for the efficacy and safety of statin therapy. Lancet. 10.1016/S0140-6736(16)31357-5

Dafale NA, Semwal UP, Rajput RK, and Singh GN. 2016. Selection of appropriate analytical tools to determine the potency and bioactivity of antibiotics and antibiotic resistance. Journal of Pharmaceutical Analysis 6:207-213.

http://dx.doi.org/10.1016/j.jpha.2016.05.006 
679 Deshpande A, Pasupuleti V, and Rothberg MB. 2015. Statin Therapy and Mortality from Sepsis:

680 A Meta-analysis of Randomized Trials. Am J Med 128:410-417 e411.

681

10.1016/j.amjmed.2014.10.057

682 Eaton LC, Erdos GW, Vreeland NL, and Ingram LO. 1981. Failure of Escherichia coli to alter its

683 fatty acid composition in response to cholesterol-induced changes in membrane fluidity. $J$

$684 \quad$ Bacteriol 146:1151-1153.

685 Elewa HF, El-Remessy AB, Somanath PR, and Fagan SC. 2010. Diverse effects of statins on

686 angiogenesis: new therapeutic avenues. Pharmacotherapy 30:169-176. 10.1592/phco.30.2.169

688

689

690

691

692 693

694

695

696

697

698

699

700

701

702

703
Emani S, Gunjiganur GV, and Mehta DS. 2014. Determination of the antibacterial activity of simvastatin against periodontal pathogens, Porphyromonas gingivalis and Aggregatibacter actinomycetemcomitans: An in vitro study. Contemp Clin Dent 5:377-382. 10.4103/0976237X.137959

Endo A. 2010. A historical perspective on the discovery of statins. Proc Jpn Acad Ser B Phys Biol Sci 86:484-493.

Farmer AR, Murray CK, Mende K, Akers KS, Zera WC, Beckius ML, and Yun HC. 2013. Effect of HMG-CoA reductase inhibitors on antimicrobial susceptibilities for gram-negative rods. J Basic Microbiol 53:336-339. 10.1002/jobm.201100614

Farsaei S, Khalili H, and Farboud ES. 2012. Potential role of statins on wound healing: review of the literature. Int Wound J 9:238-247. 10.1111/j.1742-481X.2011.00888.x

Fernandez L, Breidenstein EB, and Hancock RE. 2011. Creeping baselines and adaptive resistance to antibiotics. Drug Resist Updat 14:1-21. 10.1016/j.drup.2011.01.001

Fitzmaurice GJ, McWilliams B, Nolke L, Redmond JM, McGuinness JG, and O'Donnell ME. 2014. Do statins have a role in the promotion of postoperative wound healing in cardiac surgical patients? Ann Thorac Surg 98:756-764. 10.1016/j.athoracsur.2014.02.089 
704 Foster TJ, Geoghegan JA, Ganesh VK, and Hook M. 2014. Adhesion, invasion and evasion: the

705

706

707

708

709

710

711

712

713

714

715

716

717

718

719

720

721

722

723

724

725

726

727 many functions of the surface proteins of Staphylococcus aureus. Nat Rev Microbiol 12:49-62. 10.1038/nrmicro3161

Francino MP. 2016. Antibiotics and the Human Gut Microbiome: Dysbioses and Accumulation of Resistances. Front Microbiol 6:1543. 10.3389/fmicb.2015.01543

Friesen JA, and Rodwell VW. 2004. The 3-hydroxy-3-methylglutaryl coenzyme-A (HMG-CoA) reductases. Genome Biol 5:248. 10.1186/gb-2004-5-11-248

Frostegard J, Zhang Y, Sun J, Yan K, and Liu A. 2016. Oxidized Low-Density Lipoprotein (OxLDL)-Treated Dendritic Cells Promote Activation of T Cells in Human Atherosclerotic Plaque and Blood, Which Is Repressed by Statins: microRNA let-7c Is Integral to the Effect. J Am Heart Assoc 5. 10.1161/JAHA.116.003976

Gazzerro P, Proto MC, Gangemi G, Malfitano AM, Ciaglia E, Pisanti S, Santoro A, Laezza C, and Bifulco M. 2012. Pharmacological actions of statins: a critical appraisal in the management of cancer. Pharmacol Rev 64:102-146. 10.1124/pr.111.004994

Gombart AF. 2009. The vitamin D-antimicrobial peptide pathway and its role in protection against infection. Future Microbiol 4:1151-1165. 10.2217/fmb.09.87

Graziano TS, Cuzzullin MC, Franco GC, Schwartz-Filho HO, de Andrade ED, Groppo FC, and Cogo-Muller K. 2015. Statins and Antimicrobial Effects: Simvastatin as a Potential Drug against Staphylococcus aureus Biofilm. PLoS One 10:e0128098.

10.1371/journal.pone.0128098

Griffith R, Creely D, Revell P, Dunne WM, and Shortridge D. 2009. Comparison of Three Reference Methods for Testing Susceptibility of Staphylococci to TrimethoprimSulfamethoxazole. Journal of Clinical Microbiology 47:3726-3728. 10.1128/JCM.0045109 
728 Haeri MR, White K, Qharebeglou M, and Ansar MM. 2015. Cholesterol suppresses antimicrobial effect of statins. Iran J Basic Med Sci 18:1253-1256.

730

Hanson BR, and Neely MN. 2012. Coordinate regulation of Gram-positive cell surface components. Curr Opin Microbiol 15:204-210. 10.1016/j.mib.2011.12.011

Harrold M. 2013. Antihyperlipoproteinemics and Inhibitors of Cholesterol BIosynthesis. In: Lemke TL, Williams DA, Roche VF, and Zito SW, eds. Foye's Principles of Medicinal Chemistry. 7 ed. Philadelphia, United States of America: Lippincott Williams \& Wilkins.

Hennessy E, Adams C, Reen FJ, and O'Gara F. 2016. Is There Potential for Repurposing Statins as Novel Antimicrobials? Antimicrob Agents Chemother 60:5111-5121. 10.1128/AAC.00192-16

Heuston S, Begley M, Gahan CG, and Hill C. 2012. Isoprenoid biosynthesis in bacterial pathogens. Microbiology 158:1389-1401. 10.1099/mic.0.051599-0

Howe K, Sanat F, Thumser AE, Coleman T, and Plant N. 2011. The statin class of HMG-CoA reductase inhibitors demonstrate differential activation of the nuclear receptors PXR, CAR and FXR, as well as their downstream target genes. Xenobiotica 41:519-529. $10.3109 / 00498254.2011 .569773$

Hughes D, and Andersson DI. 2017. Evolutionary Trajectories to Antibiotic Resistance. Annu Rev Microbiol 71:579-596. 10.1146/annurev-micro-090816-093813

Hurley HJ, Knepper BC, Price CS, Mehler PS, Burman WJ, and Jenkins TC. 2013. Avoidable antibiotic exposure for uncomplicated skin and soft tissue infections in the ambulatory care setting. Am J Med 126:1099-1106. 10.1016/j.amjmed.2013.08.016

Janda S, Young A, Fitzgerald JM, Etminan M, and Swiston J. 2010. The effect of statins on mortality from severe infections and sepsis: a systematic review and meta-analysis. $J$ Crit Care 25:656 e657-622. 10.1016/j.jcrc.2010.02.013 
752 Jerwood S, and Cohen J. 2008. Unexpected antimicrobial effect of statins. J Antimicrob

$753 \quad$ Chemother 61:362-364. 10.1093/jac/dkm496

754 Kadmiel M, and Cidlowski JA. 2013. Glucocorticoid receptor signaling in health and disease. Trends Pharmacol Sci 34:518-530. 10.1016/j.tips.2013.07.003

756 Kantola T, Backman JT, Niemi M, Kivisto KT, and Neuvonen PJ. 2000. Effect of fluconazole on 757 plasma fluvastatin and pravastatin concentrations. Eur J Clin Pharmacol 56:225-229.

758 Khutoryanskiy VV. 2015. Supramolecular materials: Longer and safer gastric residence. Nat 759 Mater 14:963-964. 10.1038/nmat4432

760 761

Kocsis E, Kristóf K, Hermann P, and Rozgonyi F. 2010. A comparative review on the pathogenicity and virulence factors of meticillin-resistant and meticillin-susceptible Staphylococcus aureus. Reviews in Medical Microbiology 21:31-37. 10.1097/MRM.0b013e3283393cd4

Kohanski MA, DePristo MA, and Collins JJ. 2010. Sublethal antibiotic treatment leads to multidrug resistance via radical-induced mutagenesis. Mol Cell 37:311-320. 10.1016/j.molcel.2010.01.003

Kozarov E, Padro T, and Badimon L. 2014. View of statins as antimicrobials in cardiovascular risk modification. Cardiovascular Research 102:362-374. 10.1093/cvr/cvu058

Kruszewska H, Zareba T, and Tyski S. 2006. Estimation of antimicrobial activity of selected nonantibiotic products. Acta Pol Pharm 63:457-460.

Kruszewska H, Zareba T, and Tyski S. 2010. Examination of antimicrobial activity of selected non-antibiotic products. Acta Pol Pharm 67:733-736.

Laudy AE, Kulinska E, and Tyski S. 2017. The Impact of Efflux Pump Inhibitors on the Activity of Selected Non-Antibiotic Medicinal Products against Gram-Negative Bacteria. Molecules 22. 10.3390/molecules22010114 
776 Lebeer S, Vanderleyden J, and De Keersmaecker SC. 2010. Host interactions of probiotic

777 bacterial surface molecules: comparison with commensals and pathogens. Nat Rev

$778 \quad$ Microbiol 8:171-184. 10.1038/nrmicro2297

779 Lee HB, Peart TE, Svoboda ML, and Backus S. 2009. Occurrence and fate of rosuvastatin, 780 rosuvastatin lactone, and atorvastatin in Canadian sewage and surface water samples.

$781 \quad$ Chemosphere 77:1285-1291. 10.1016/j.chemosphere.2009.09.068

782 Levison ME, and Levison JH. 2009. Pharmacokinetics and pharmacodynamics of antibacterial 783 agents. Infect Dis Clin North Am 23:791-815, vii. 10.1016/j.idc.2009.06.008

784 Li D, Zeng S, He M, and Gu AZ. 2016. Water Disinfection Byproducts Induce Antibiotic 785 Resistance-Role of Environmental Pollutants in Resistance Phenomena. Environ Sci Technol 50:3193-3201. 10.1021/acs.est.5b05113

Liao JK. 2005. Clinical implications for statin pleiotropy. Curr Opin Lipidol 16:624-629. 118. 10.1146/annurev.pharmtox.45.120403.095748

Liu M, Lu J, Muller P, Turnbull L, Burke CM, Schlothauer RC, Carter DA, Whitchurch CB, and Harry EJ. 2015. Antibiotic-specific differences in the response of Staphylococcus aureus to treatment with antimicrobials combined with manuka honey. Front Microbiol 5:779. 10.3389/fmicb.2014.00779

Malanovic N, and Lohner K. 2016. Gram-positive bacterial cell envelopes: The impact on the 
801 Mangin M, Sinha R, and Fincher K. 2014. Inflammation and vitamin D: the infection connection.

$802 \quad$ Inflamm Res 63:803-819.10.1007/s00011-014-0755-z

803 Marshall TG. 2006. Are statins analogues of vitamin D? Lancet 368:1234; author reply 1235.

$804 \quad 10.1016 / \mathrm{S} 0140-6736(06) 69509-3$

805 Masadeh M, Mhaidat N, Alzoubi K, Al-Azzam S, and Alnasser Z. 2012. Antibacterial activity of 806 statins: a comparative study of atorvastatin, simvastatin, and rosuvastatin. Ann Clin $807 \quad$ Microbiol Antimicrob 11:13. 10.1186/1476-0711-11-13

808 Matzneller P, Manafi M, and Zeitlinger M. 2011. Antimicrobial effect of statins: organic solvents 809 might falsify microbiological testing results. Int J Clin Pharmacol Ther 49:666-671. $810 \quad 10.5414 / \mathrm{CP} 201581$

811 McFarland AJ, Anoopkumar-Dukie S, Arora DS, Grant GD, McDermott CM, Perkins AV, and 812 Davey AK. 2014. Molecular mechanisms underlying the effects of statins in the central 813 nervous system. Int J Mol Sci 15:20607-20637. 10.3390/ijms151120607

814 Millar PJ, and Floras JS. 2014. Statins and the autonomic nervous system. Clin Sci (Lond) 815 126:401-415. 10.1042/CS20130332

816 Murphy TJ, Paterson HM, Mannick JA, and Lederer JA. 2004. Injury, sepsis, and the regulation 817 of Toll-like receptor responses. J Leukoc Biol 75:400-407. 10.1189/jlb.0503233

818 Ottmar KJ, Colosi LM, and Smith JA. 2012. Fate and transport of atorvastatin and simvastatin 819 drugs during conventional wastewater treatment. Chemosphere 88:1184-1189.

$820 \quad 10.1016 / \mathrm{j}$. chemosphere.2012.03.066

821 Ou SY, Chu H, Chao PW, Ou SM, Lee YJ, Kuo SC, Li SY, Shih CJ, and Chen YT. 2014. Effect of 822 the use of low and high potency statins and sepsis outcomes. Intensive Care Med 823 40:1509-1517. 10.1007/s00134-014-3418-1 
824 Parihar SP, Hartley MA, Hurdayal R, Guler R, and Brombacher F. 2016. Topical Simvastatin as

825 Host-Directed Therapy against Severity of Cutaneous Leishmaniasis in Mice. Sci Rep

$826 \quad 6: 33458.10 .1038 / \operatorname{srep} 33458$

827 Park B, and Liu GY. 2012. Targeting the host-pathogen interface for treatment of Staphylococcus

828 aureus infection. Semin Immunopathol 34:299-315. 10.1007/s00281-011-0297-1

829 Paumelle R, and Staels B. 2007. Peroxisome proliferator-activated receptors mediate pleiotropic

$830 \quad$ actions of statins. Circ Res 100:1394-1395. 10.1161/01.RES.0000269334.42814.d2

831 Quinn M, Moody C, Tunnicliffe B, Khan Z, Manji M, Gudibande S, Murphy N, Whitehouse T,

832 Snelson C, and Veenith T. 2016. Systematic review of statins in sepsis: There is no

833 evidence of dose response. Indian J Crit Care Med 20:534-541. 10.4103/0972-

$834 \quad 5229.190366$

835 Quivey R. 2014. Reducing dental caries. Google Patents: University Of Rochester. Google

836 Patents: University Of Rochester.

837 Radwan S, and Ezzat O. 2012. Antimicrobial Effect and Immunomodulation of Atorvastatin. $J$ $838 \quad$ Am Sci 8:1012-1016.

839 Reen FJ, Flynn S, Woods DF, Dunphy N, Chroinin MN, Mullane D, Stick S, Adams C, and

840 O'Gara F. 2016. Bile signalling promotes chronic respiratory infections and antibiotic

$841 \quad$ tolerance. Sci Rep 6:29768. 10.1038/srep29768

842 Reinoso RF, Sanchez Navarro A, Garcia MJ, and Prous JR. 2002. Preclinical pharmacokinetics of $843 \quad$ statins. Methods Find Exp Clin Pharmacol 24:593-613.

844 Rittirsch D, Flierl MA, and Ward PA. 2008. Harmful molecular mechanisms in sepsis. Nat Rev Immunol 8:776-787. 10.1038/nri2402

846 Rosenfeld Y, and Shai Y. 2006. Lipopolysaccharide (Endotoxin)-host defense antibacterial

847 peptides interactions: role in bacterial resistance and prevention of sepsis. Biochim

848

Biophys Acta 1758:1513-1522. 10.1016/j.bbamem.2006.05.017 
849 Ruiz N, Kahne D, and Silhavy TJ. 2009. Transport of lipopolysaccharide across the cell

850 envelope: the long road of discovery. Nat Rev Microbiol 7:677-683. 10.1038/nrmicro2184

851 Sarabhai S, Dhaliwal LK, Capalash N, and Sharma P. 2015. Effect of atorvastatin and rosuvastatin on quorum sensing, biofilm formation and bacterial motilities of Pseudomonas aeruginosa. International Journal of Pharma and Bio Sciences 6:(B) 1-8.

Sarr FS, Andre C, and Guillaume YC. 2008. Statins (HMG-coenzyme A reductase inhibitors)biomimetic membrane binding mechanism investigated by molecular chromatography. $J$

Schaap FG, Trauner M, and Jansen PL. 2014. Bile acid receptors as targets for drug development. Nat Rev Gastroenterol Hepatol 11:55-67. 10.1038/nrgastro.2013.151

Shanholtzer CJ, Peterson LR, Mohn ML, Moody JA, and Gerding DN. 1984. MBCs for Staphylococcus aureus as determined by macrodilution and microdilution techniques. Antimicrob Agents Chemother 26:214-219.

Shi JH, Wang Q, Pan DQ, Liu TT, and Jiang M. 2016. Characterization of interactions of simvastatin, pravastatin, fluvastatin, and pitavastatin with bovine serum albumin: multiple spectroscopic and molecular docking. J Biomol Struct Dyn:1-18.

868 Silhavy TJ, Kahne D, and Walker S. 2010. The bacterial cell envelope. Cold Spring Harb Perspect Biol 2:a000414. 10.1101/cshperspect.a000414 Environment and Its Relevance to Environmental Regulators. Front Microbiol 7:1728. 10.3389/fmicb.2016.01728 
873 Sorensen OE, and Borregaard N. 2016. Neutrophil extracellular traps - the dark side of $874 \quad$ neutrophils. J Clin Invest 126:1612-1620. 10.1172/JCI84538

875 Terblanche M, Almog Y, Rosenson RS, Smith TS, and Hackam DG. 2007. Statins and sepsis: multiple modifications at multiple levels. Lancet Infect Dis 7:358-368. 10.1016/S14733099(07)70111-1

878

879

880

881

882

883

884

885

886

887

888

889

890

891

892

893

894

895

896

Thangamani S, Mohammad H, Abushahba MF, Hamed MI, Sobreira TJ, Hedrick VE, Paul LN, and Seleem MN. 2015. Exploring simvastatin, an antihyperlipidemic drug, as a potential topical antibacterial agent. Sci Rep 5:16407. 10.1038/srep16407

Ting M, Whitaker EJ, and Albandar JM. 2016. Systematic review of the in vitro effects of statins on oral and perioral microorganisms. Eur J Oral Sci 124:4-10. 10.1111/eos.12239

Tobert JA. 2003. Lovastatin and beyond: the history of the HMG-CoA reductase inhibitors. Nat Rev Drug Discov 2:517-526. 10.1038/nrd1112

Turnidge J, and Paterson DL. 2007. Setting and revising antibacterial susceptibility breakpoints. Clin Microbiol Rev 20:1391-408. 10.1128/CMR.00047-06

US Preventive Services Task Force. 2016. Statin use for the primary prevention of cardiovascular disease in adults: Us preventive services task force recommendation statement. JAMA 316:1997-2007. 10.1001/jama.2016.15450

Vera S, Martinez R, Gormaz JG, Gajardo A, Galleguillos F, and Rodrigo R. 2015. Novel relationships between oxidative stress and angiogenesis-related factors in sepsis: New biomarkers and therapies. Ann Med 47:289-300. 10.3109/07853890.2015.1029967

Vukelic S, Stojadinovic O, Pastar I, Vouthounis C, Krzyzanowska A, Das S, Samuels HH, and Tomic-Canic M. 2010. Farnesyl pyrophosphate inhibits epithelialization and wound healing through the glucocorticoid receptor. J Biol Chem 285:1980-1988. 10.1074/jbc.M109.016741 
897 Wales AD, and Davies RH. 2015. Co-Selection of Resistance to Antibiotics, Biocides and Heavy

898 Metals, and Its Relevance to Foodborne Pathogens. Antibiotics (Basel) 4:567-604.

899 10.3390/antibiotics4040567

900

901

902

903

904

905

906

907

908

909

910

911

912

913

914

915

916

917

918

Treatments to Enhance Innate Immunity. Can Statins Improve Neutrophil Functions and Clinical Outcomes in COPD? J Clin Med 5. 10.3390/jcm5100089

Wang CC, Yang PW, Yang SF, Hsieh KP, Tseng SP, and Lin YC. 2015. Topical simvastatin promotes healing of Staphylococcus aureus-contaminated cutaneous wounds. Int Wound J. 10.1111/iwj.12431

Weinstein LI, Revuelta A, and Pando RH. 2015. Catecholamines and acetylcholine are key regulators of the interaction between microbes and the immune system. Ann N Y Acad Sci 1351:39-51. 10.1111/nyas.12792

Welsh AM, Kruger P, and Faoagali J. 2009. Antimicrobial action of atorvastatin and rosuvastatin. Pathology 41:689-691. 10.3109/00313020903305860

Wittebole X, Castanares-Zapatero D, and Laterre PF. 2010. Toll-like receptor 4 modulation as a strategy to treat sepsis. Mediators Inflamm 2010:568396. 10.1155/2010/568396

World Health Organization. Antimicrobial resistance. Available at http://www.who.int/mediacentre/factsheets/fs194/en/ (accessed 08 December 2016.

World Health Organization. Antimicrobial resistance: Global Report on Surveillance. Available at http://www.who.int/drugresistance/documents/surveillancereport/en/ (accessed 08 December 2016.

Wu HJ, Wang AH, and Jennings MP. 2008. Discovery of virulence factors of pathogenic bacteria. Curr Opin Chem Biol 12:93-101. 10.1016/j.cbpa.2008.01.023

Xia G, Kohler T, and Peschel A. 2010. The wall teichoic acid and lipoteichoic acid polymers of Staphylococcus aureus. Int J Med Microbiol 300:148-154. 10.1016/j.ijmm.2009.10.001 
922 Yang Z, Huang YC, Koziel H, de Crom R, Ruetten H, Wohlfart P, Thomsen RW, Kahlert JA, 923 Sorensen HT, Jozefowski S, Colby A, and Kobzik L. 2014. Female resistance to 924 pneumonia identifies lung macrophage nitric oxide synthase-3 as a therapeutic target. Elife 3. 10.7554/eLife.03711

926 Zhernakova A, Kurilshikov A, Bonder MJ, Tigchelaar EF, Schirmer M, Vatanen T, Mujagic Z, 927 Vila AV, Falony G, Vieira-Silva S, Wang J, Imhann F, Brandsma E, Jankipersadsing SA, 928 Joossens M, Cenit MC, Deelen P, Swertz MA, LifeLines cohort s, Weersma RK, Feskens EJ, Netea MG, Gevers D, Jonkers D, Franke L, Aulchenko YS, Huttenhower C, Raes J, Hofker MH, Xavier RJ, Wijmenga C, and Fu J. 2016. Population-based metagenomics analysis reveals markers for gut microbiome composition and diversity. Science 352:565569. $10.1126 /$ science.aad3369 


\section{Table $\mathbf{1}$ (on next page)}

Compiled antimicrobial susceptibility results of statins against various Gram-positive bacteria reported in literature. ${ }^{\text {a }}$

${ }^{a}$ The dilution methods for (Alshammari 2016), (Bergman et al. 2011), (Quivey 2014), (Welsh et al. 2009), and (Ting et al. 2016) were described in the respective studies. All other studies were tested according to the broth microdilution method stipulated by the Clinical and Laboratory Standards Institute (CLSI), formerly known as National Committee for Clinical Laboratory Standards (NCCLS).

${ }^{b}$ ATCC, American Type Culture Collection.

c All studies were tested with Mueller Hinton broth unless specified. Solvent types and solvent concentrations used for water insoluble statins (ATV, LVS, PTV, and SMV) were listed as reported in the various references. DMSO, dimethyl sulfoxide.

${ }^{d}$ ATV, atorvastatin; FLV, fluvastatin; LVS, lovastatin; MIC, minimum inhibitory concentration; PRV, pravastatin; PTV, pitavastatin; RSV, rosuvastatin; SMV, simvastatin. 


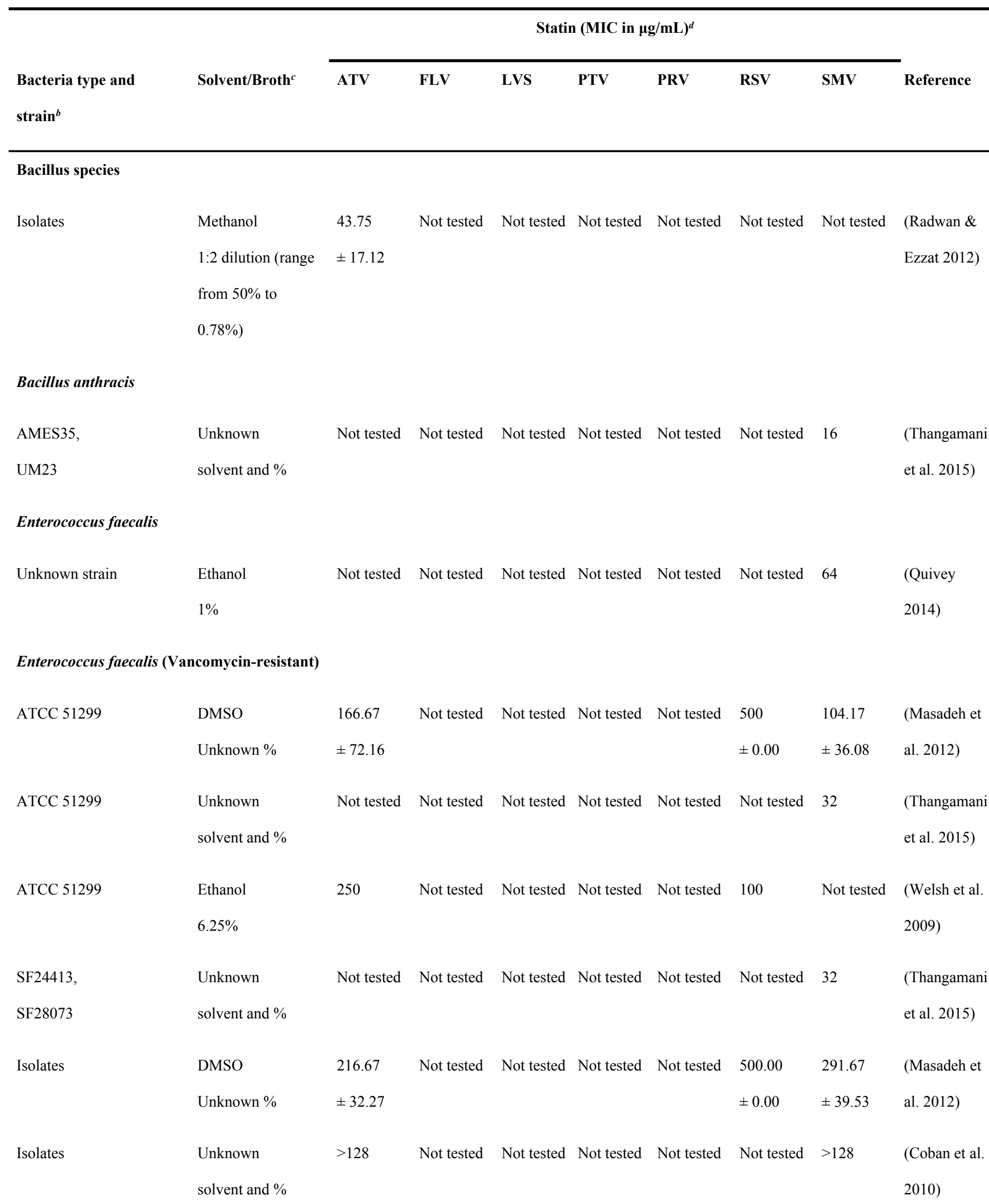




\begin{tabular}{|c|c|c|c|c|c|c|c|c|c|}
\hline ATCC 7080, & Unknown & Not tested & Not tested & Not tested & Not tested & Not tested & Not tested & 32 & (Thangamani \\
\hline ATCC 14506 & solvent and $\%$ & & & & & & & & et al. 2015) \\
\hline \multirow[t]{2}{*}{ ATCC 19433} & DMSO & 83.33 & Not tested & Not tested & Not tested & Not tested & $333.33 \pm$ & 52.08 & (Masadeh et \\
\hline & Unknown \% & \pm 36.08 & & & & & 144.33 & \pm 18.04 & al. 2012) \\
\hline \multirow[t]{2}{*}{ ATCC 29212} & Unknown & $>128$ & Not tested & Not tested & Not tested & Not tested & Not tested & 64 & (Coban et al. \\
\hline & solvent and $\%$ & & & & & & & & 2010) \\
\hline \multirow[t]{2}{*}{ ATCC 29212} & Ethanol & 250 & Not tested & Not tested & Not tested & Not tested & 100 & Not tested & (Welsh et al. \\
\hline & $6.25 \%$ & & & & & & & & 2009) \\
\hline \multirow[t]{2}{*}{ ATCC 29212} & DMSO & $>250$ & Not tested & Not tested & Not tested & $>250$ & Not tested & $>250$ & (Graziano et \\
\hline & $2.5 \%$ & & & & & & & & al. 2015) \\
\hline ATCC 49532, & Unknown & Not tested & Not tested & Not tested & Not tested & Not tested & Not tested & 32 & (Thangamani \\
\hline ATCC 49533, & solvent and \% & & & & & & & & et al. 2015) \\
\hline \multicolumn{10}{|c|}{ НH22, ММH594, } \\
\hline \multicolumn{10}{|l|}{ SF24397 } \\
\hline \multirow[t]{2}{*}{ Isolates } & DMSO & 95.83 & Not tested & Not tested & Not tested & Not tested & 333.33 & 291.67 & (Masadeh et \\
\hline & Unknown \% & \pm 22.09 & & & & & \pm 0.00 & \pm 39.53 & al. 2012) \\
\hline \multirow[t]{2}{*}{ Isolates } & Unknown & $>128$ & Not tested & Not tested & Not tested & Not tested & Not tested & $>128$ & (Coban et al. \\
\hline & solvent and \% & & & & & & & & 2010) \\
\hline
\end{tabular}

Enterococcus faecium

Unknown strain

Ethanol

Not tested Not tested Not tested Not tested Not tested Not tested 64

(Quivey

$1 \%$

2014)

Enterococcus faecium (Vancomycin-resistant)

\begin{tabular}{|c|c|c|c|c|c|c|c|c|c|}
\hline ATCC 700221, & Unknown & Not tested & Not tested & Not tested & Not tested & Not tested & Not tested & 32 & (Thangamani \\
\hline E0120, ERV102 & solvent and \% & & & & & & & & et al. 2015) \\
\hline Isolates & Unknown & $>128$ & Not tested & Not tested & Not tested & Not tested & Not tested & $>128$ & (Coban et al. \\
\hline & solvent and \% & & & & & & & & 2010) \\
\hline
\end{tabular}

Enterococcus faecium (Vancomycin-sensitive)

ATCC 6569,

Unknown

Not tested Not tested Not tested Not tested Not tested Not tested 32

(Thangamani 
E1162

Isolates solvent and $\%$

Unknown

solvent and \% et al. 2015)

(Coban et al.

2010)

\section{Lactobacillus casei}

Unknown strain

Not

Not tested Not tested Not tested Not tested Not tested Not tested 7.8

(Ting et al.

specified

Listeria monocytogenes

ATCC 13932,

Unknown

Not tested

Not test

ATCC 19111,

solvent and $\%$

et al. 2015

ATCC 19112,

ATCC 19114,

F4244, J0161

Staphylococci (Methicillin-resistant coagulase negative, MRCoNS)

Isolates

Unknown

$>128$

Not tes

(Coban et al.

solvent and $\%$

2010)

Staphylococcus aureus

Unknown strain

Ethanol

Not tested

Not tested

Not tested Not tested Not tested Not tested 64

(Quivey

$1 \%$

2014)

Staphylococcus aureus (Methicillin-resistant, MRSA)

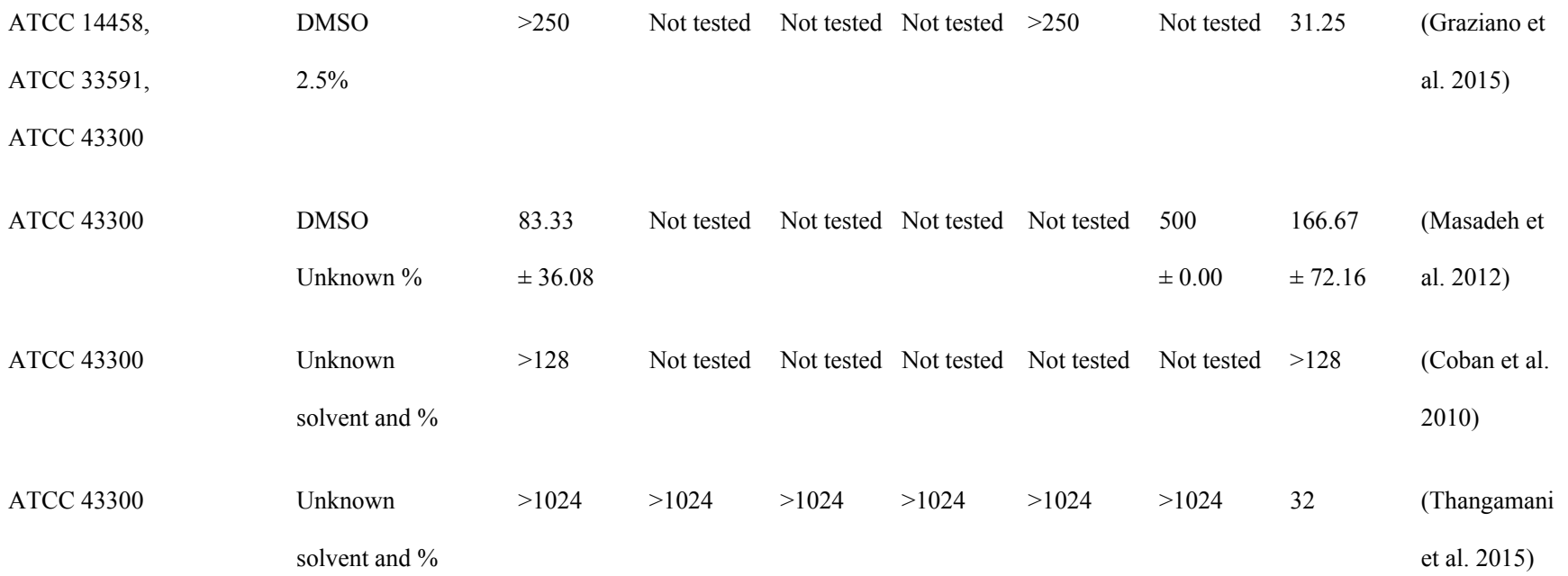




\begin{tabular}{|c|c|c|c|c|c|c|c|c|c|}
\hline \multirow[t]{2}{*}{ ATCC 49476} & Ethanol & \multirow[t]{2}{*}{250} & \multirow[t]{2}{*}{ Not tested } & \multirow[t]{2}{*}{ Not tested } & \multirow[t]{2}{*}{ Not tested } & \multirow[t]{2}{*}{ Not tested } & \multirow[t]{2}{*}{100} & \multirow[t]{2}{*}{ Not tested } & \multirow[t]{2}{*}{ (Welsh et al. } \\
\hline & $6.25 \%$ & & & & & & & & \\
\hline АТCC BAA-44, & Unknown & Not tested & Not tested & Not tested & Not tested & Not tested & Not tested & 32 & (Thangamani \\
\hline NRS70, NRS71, & solvent and \% & & & & & & & & et al. 2015) \\
\hline \multicolumn{10}{|l|}{ NRS108, NRS119, } \\
\hline \multicolumn{10}{|l|}{ NRS123 } \\
\hline NRS100, NRS194 & Unknown & Not tested & Not tested & Not tested & Not tested & Not tested & Not tested & 64 & (Thangamani \\
\hline & solvent and \% & & & & & & & & et al. 2015) \\
\hline USA100, USA200, & Unknown & Not tested & Not tested & Not tested & Not tested & Not tested & Not tested & 32 & (Thangamani \\
\hline USA300, USA400, & solvent and \% & & & & & & & & et al. 2015) \\
\hline \multicolumn{10}{|l|}{ USA500, USA700, } \\
\hline \multicolumn{10}{|l|}{ USA800, USA1000, } \\
\hline \multicolumn{10}{|l|}{ USA1100 } \\
\hline \multirow[t]{2}{*}{ Isolates } & DMSO & 108.33 & Not tested & Not tested & Not tested & Not tested & 500.00 & 116.67 & (Masadeh et \\
\hline & Unknown \% & \pm 27.36 & & & & & \pm 0.00 & \pm 30.19 & al. 2012) \\
\hline \multirow[t]{2}{*}{ Isolates } & Unknown & $>128$ & Not tested & Not tested & Not tested & Not tested & Not tested & $>128$ & (Coban et al. \\
\hline & solvent and \% & & & & & & & & 2010) \\
\hline \multirow[t]{3}{*}{ Isolates } & Methanol & Not tested & $>200$ & Not tested & Not tested & Not tested & Not tested & 74.9 & (Jerwood \& \\
\hline & 1:2 dilution (range & & (mean) & & & & & (mean) & Cohen 2008) \\
\hline & from $50 \%$ to $0.2 \%$ ) & & & & & & & & \\
\hline \multirow[t]{4}{*}{ Isolates } & Methanol & 37.5 & Not tested & Not tested & Not tested & Not tested & Not tested & Not tested & (Radwan \& \\
\hline & 1:2 dilution (range & \pm 13.98 & & & & & & & Ezzat 2012) \\
\hline & from $50 \%$ to & & & & & & & & \\
\hline & $0.78 \%)$ & & & & & & & & \\
\hline
\end{tabular}

Staphylococcus aureus (Methicillin-sensitive, MSSA)

\begin{tabular}{|c|c|c|c|c|c|c|c|c|c|}
\hline ATCC 6538 & DMSO & $>250$ & Not tested & Not tested & Not tested & $>250$ & Not tested & 31.25 & (Graziano et \\
\hline & $2.5 \%$ & & & & & & & & al. 2015) \\
\hline ATCC 6538 & Unknown & Not tested & Not tested & Not tested & Not tested & Not tested & Not tested & 32 & (Thangamani \\
\hline & solvent and $\%$ & & & & & & & & et al. 2015) \\
\hline ATCC 25213 & DMSO & 41.67 & Not tested & Not tested & Not tested & Not tested & 208.33 & 26.04 & (Masadeh et \\
\hline
\end{tabular}




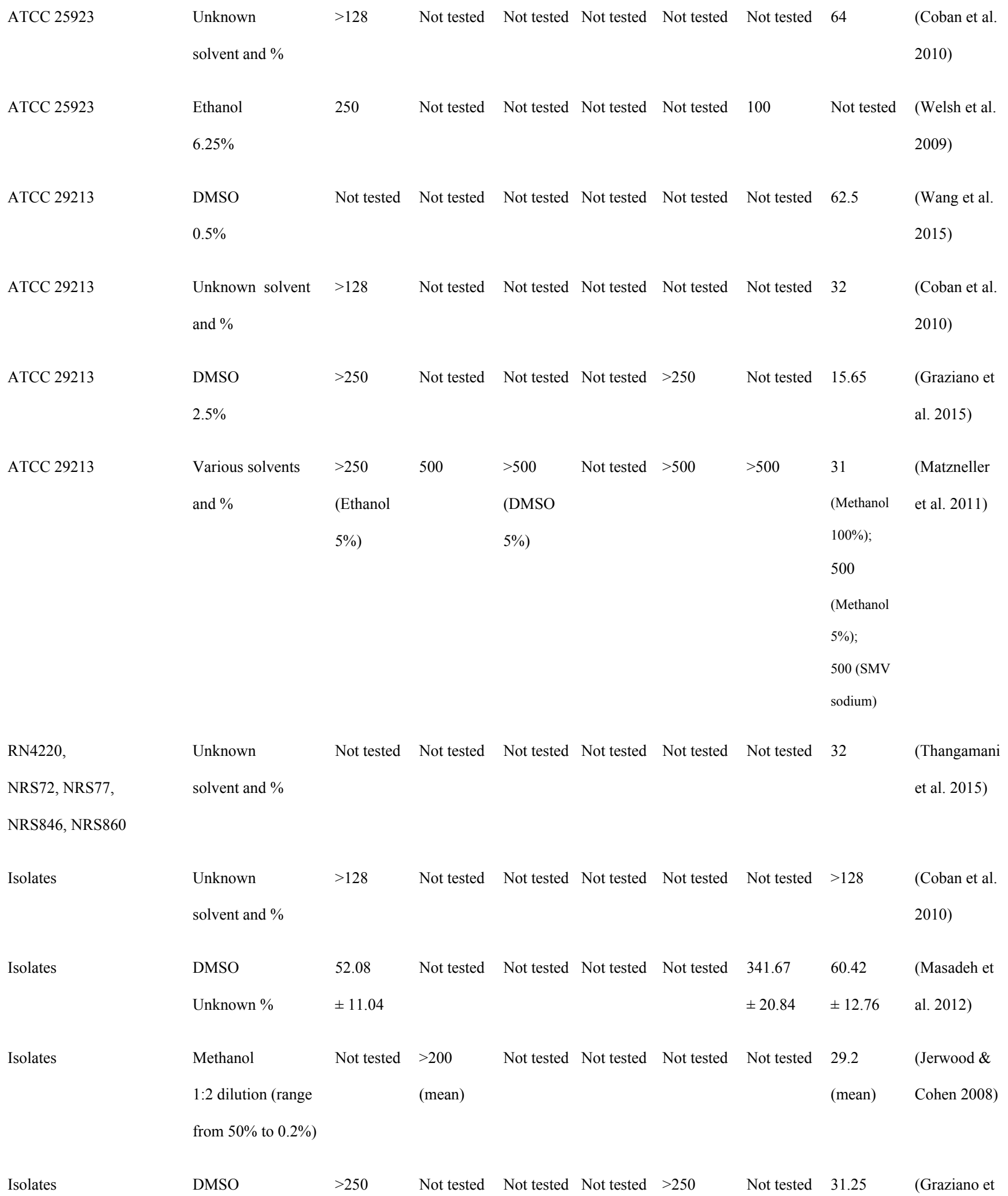


Staphylococcus aureus (Vancomycin-intermediate, VISA)

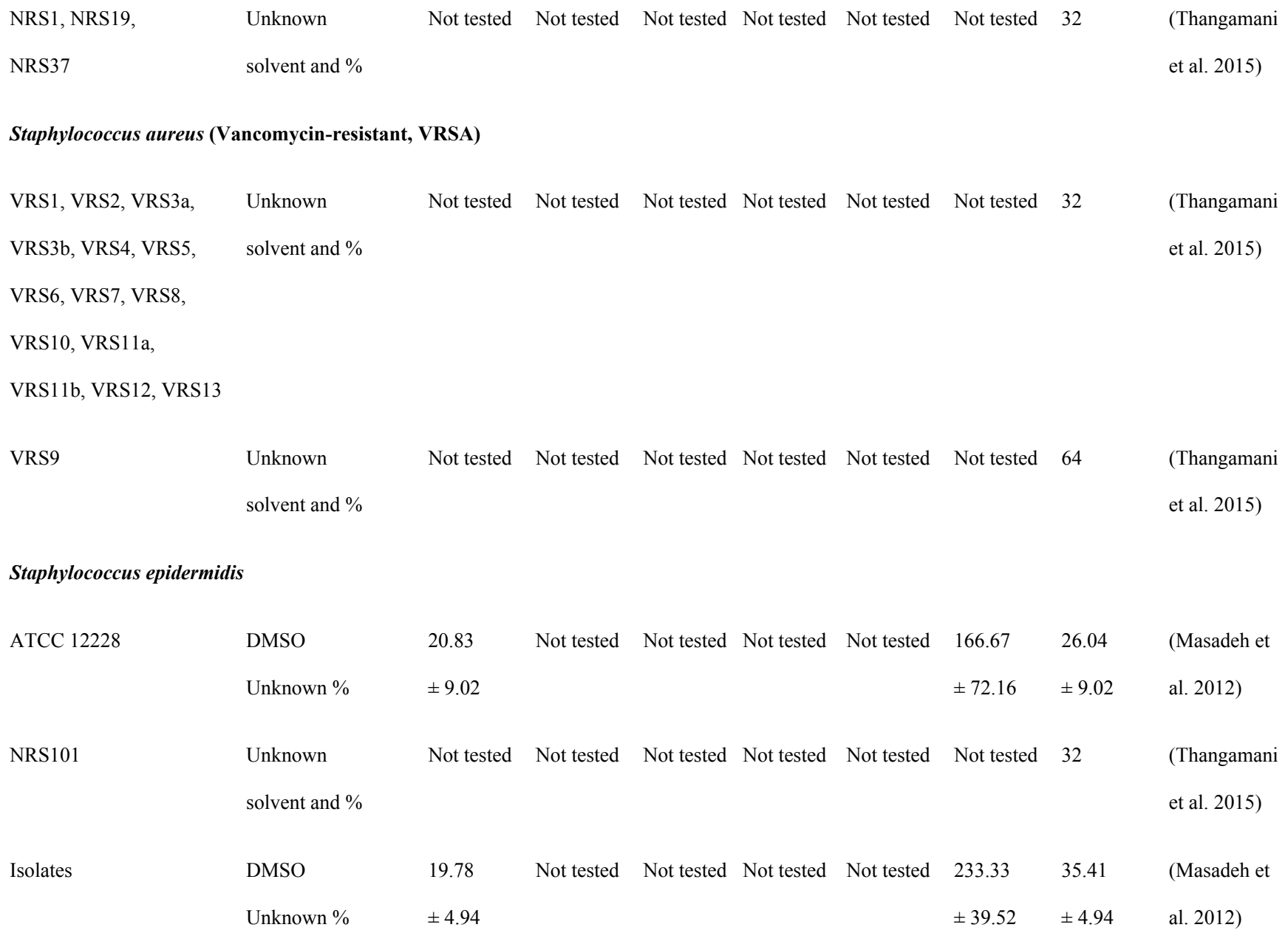

Streptococcus anginosus

Unknown strain

Not

Not tested

Not test

Not tested Not tested Not tested

Not tested

7.8

(Ting et al.

specified

Streptococcus mutans

ATCC 25175

DMSO

100

Not tested Not tested Not tested 200

100

15.6

(Alshammari

1:2 dilution (range

2016)

from $50 \%$ to $0.2 \%$ )

UA159

Ethanol

Not tested

Not tested

Not tested Not tested Not tested Not tested 16

(Quivey

$1 \%$ 


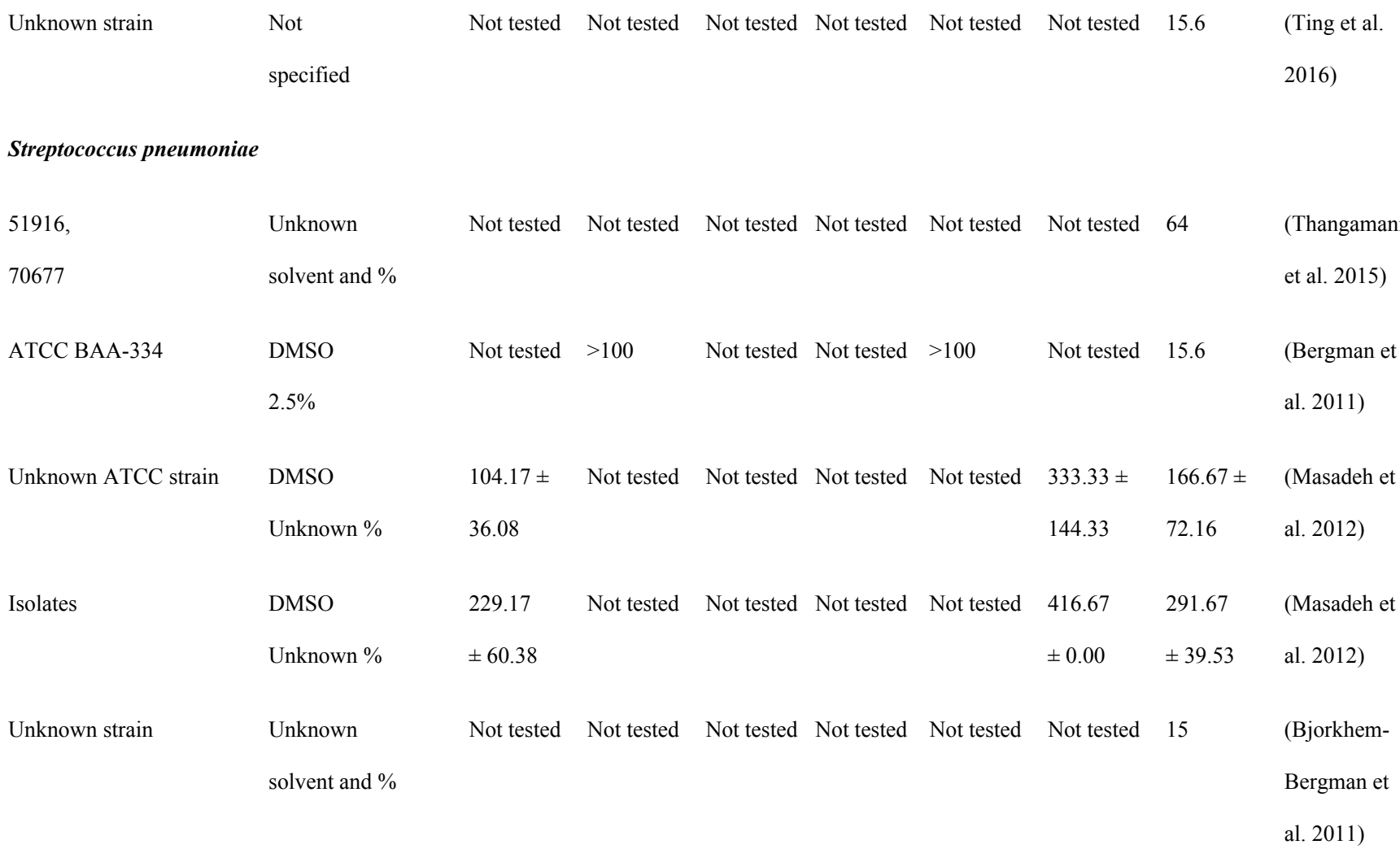

Streptococcus pyogenes

\begin{tabular}{|c|c|c|c|c|c|c|c|c|c|}
\hline \multirow[t]{2}{*}{ ATCC 19615} & DMSO & 83.33 & Not tested & Not tested & Not tested & Not tested & 166.67 & 62.5 & (Masadeh et \\
\hline & Unknown \% & \pm 36.08 & & & & & \pm 72.16 & \pm 0.00 & al. 2012) \\
\hline Isolates & DMSO & 133.33 & Not tested & Not tested & Not tested & Not tested & 275.00 & 145.83 & (Masadeh et \\
\hline
\end{tabular}

Streptococcus salivarius

\begin{tabular}{|c|c|c|c|c|c|c|c|c|c|}
\hline \multirow[t]{3}{*}{ ATCC 2593} & DMSO & 100 & Not tested & Not tested & Not tested & 200 & 100 & 7.8 & (Alshammar \\
\hline & $1: 2$ dilu & & & & & & & & 2016) \\
\hline & from 50 & & & & & & & & \\
\hline \multirow[t]{2}{*}{ Unknown strain } & Not & Not tested & Not tested & Not tested & Not tested & Not tested & Not tested & 7.8 & (Ting et al. \\
\hline & specifie & & & & & & & & 2016) \\
\hline
\end{tabular}

Streptococcus sanguinis (Streptococcus sanguis)

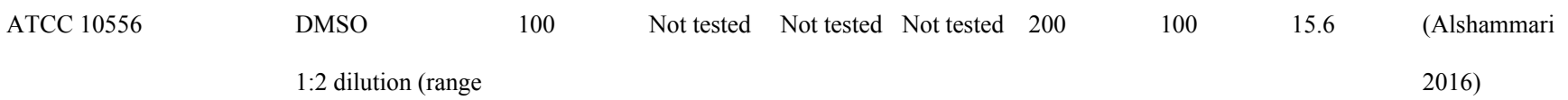


from $50 \%$ to $0.2 \%$ )

Unknown strain 


\section{Table 2 (on next page)}

Compiled antimicrobial susceptibility results of statins against various Gram-negative bacteria reported in literature. ${ }^{a}$

${ }^{a}$ The dilution methods for (Bergman et al. 2011) , (Quivey 2014), (Welsh et al. 2009), and (Ting et al. 2016) were described in the respective studies. All other studies were tested according to the broth microdilution method stipulated by the Clinical and Laboratory Standards Institute (CLSI), formerly known as National Committee for Clinical Laboratory Standards (NCCLS).

${ }^{b}$ ATCC, American Type Culture Collection.

c All studies were tested with Mueller Hinton broth unless specified. Solvent types and solvent concentrations used for water insoluble statins (ATV, LVS, PTV, and SMV) were listed as reported in the various references. DMSO, dimethyl sulfoxide.

${ }^{d}$ ATV, atorvastatin; FLV, fluvastatin; LVS, lovastatin; MIC, minimum inhibitory concentration; PRV, pravastatin; PTV, pitavastatin; RSV, rosuvastatin; SMV, simvastatin. 


\begin{tabular}{|c|c|c|c|c|c|c|c|c|c|}
\hline \multirow[b]{2}{*}{$\begin{array}{l}\text { Bacteria type and } \\
\text { strain }^{b}\end{array}$} & \multirow[b]{2}{*}{ Solvent/Broth ${ }^{c}$} & \multicolumn{7}{|c|}{ Statin $(\mathrm{MIC} \text { in } \mu \mathrm{g} / \mathrm{mL})^{d}$} & \multirow[b]{2}{*}{ Reference } \\
\hline & & ATV & FLV & LVS & PTV & PRV & RSV & SMV & \\
\hline \multicolumn{10}{|l|}{ Acinetobacter baumannii } \\
\hline ATCC 17978 & $\begin{array}{l}\text { DMSO } \\
\text { Unknown \% }\end{array}$ & $\begin{array}{l}15.62 \\
\pm 0.00\end{array}$ & Not tested & Not tested & Not tested & Not tested & $\begin{array}{l}333.33 \\
\pm 144.33\end{array}$ & $\begin{array}{l}104.17 \\
\pm 36.08\end{array}$ & $\begin{array}{l}\text { (Masadeh et } \\
\text { al. 2012) }\end{array}$ \\
\hline $\begin{array}{l}\text { ATCC BAA } 747, \\
\text { ATCC BAA } 1605, \\
\text { ATCC BAA } 19606\end{array}$ & $\begin{array}{l}\text { Unknown } \\
\text { solvent and \% }\end{array}$ & Not tested & Not tested & Not tested & Not tested & Not tested & Not tested & $>256$ & $\begin{array}{l}\text { (Thangamani } \\
\text { et al. 2015) }\end{array}$ \\
\hline Isolates & $\begin{array}{l}\text { DMSO } \\
\text { Unknown \% }\end{array}$ & $\begin{array}{l}21.87 \\
\pm 4.94\end{array}$ & Not tested & Not tested & Not tested & Not tested & $\begin{array}{l}300.00 \\
\pm 79.05\end{array}$ & $\begin{array}{l}32.29 \\
\pm 6.38\end{array}$ & $\begin{array}{l}\text { (Masadeh et } \\
\text { al. 2012) }\end{array}$ \\
\hline Isolates & $\begin{array}{l}\text { Unknown } \\
\text { solvent and \% }\end{array}$ & $>128$ & Not tested & Not tested & Not tested & Not tested & Not tested & $>128$ & $\begin{array}{l}\text { (Coban et al. } \\
2010)\end{array}$ \\
\hline Aggregatibacter actinon & etemcomitans & & & & & & & & \\
\hline Unknown ATCC strain & $\begin{array}{l}\text { DMSO } \\
1 \% \text { stock, } \\
\text { Brain heart } \\
\text { infusion broth }\end{array}$ & Not tested & Not tested & Not tested & Not tested & Not tested & Not tested & $<1$ & $\begin{array}{l}\text { (Emani et al. } \\
\text { 2014) }\end{array}$ \\
\hline Unknown strain & $\begin{array}{l}\text { Not } \\
\text { specified }\end{array}$ & Not tested & Not tested & Not tested & Not tested & Not tested & Not tested & 3.95 & $\begin{array}{l}\text { (Ting et al. } \\
\text { 2016) }\end{array}$ \\
\hline Citrobacter freundii & & & & & & & & & \\
\hline ATCC 8090 & $\begin{array}{l}\text { DMSO } \\
\text { Unknown \% }\end{array}$ & $\begin{array}{l}83.33 \\
\pm 36.08\end{array}$ & Not tested & Not tested & Not tested & Not tested & $\begin{array}{l}166.67 \\
\pm 72.16\end{array}$ & $\begin{array}{l}52.08 \\
\pm 18.04\end{array}$ & $\begin{array}{l}\text { (Masadeh et } \\
\text { al. 2012) }\end{array}$ \\
\hline Isolates & $\begin{array}{l}\text { DMSO } \\
\text { Unknown \% }\end{array}$ & $\begin{array}{l}108.33 \\
\pm 27.36\end{array}$ & Not tested & Not tested & Not tested & Not tested & $\begin{array}{l}333.33 \\
\pm 79.06\end{array}$ & $\begin{array}{l}133.33 \\
\pm 39.58\end{array}$ & $\begin{array}{l}\text { (Masadeh et } \\
\text { al. 2012) }\end{array}$ \\
\hline Enterobacter aerogenes & & & & & & & & & \\
\hline ATCC 29751 & $\begin{array}{l}\text { DMSO } \\
\text { Unknown \% }\end{array}$ & $\begin{array}{l}15.62 \\
\pm 0.00\end{array}$ & Not tested & Not tested & Not tested & Not tested & $\begin{array}{l}104.17 \\
\pm 36.08\end{array}$ & $\begin{array}{l}26.04 \\
\pm 9.02\end{array}$ & $\begin{array}{l}\text { (Masadeh et } \\
\text { al. 2012) }\end{array}$ \\
\hline
\end{tabular}


Isolates

DMSO

Unknown \%

19.78

$\pm 4.94$

Enterobacter cloacae

ATCC 13047

Isolates

DMSO

Unknown \%

$\pm 27.06$

Not tested

41.67

Not test

Not tested Not tested Not tested

$(66.67$

$\pm 0.00$

al. 2012)

\section{Escherichia coli}

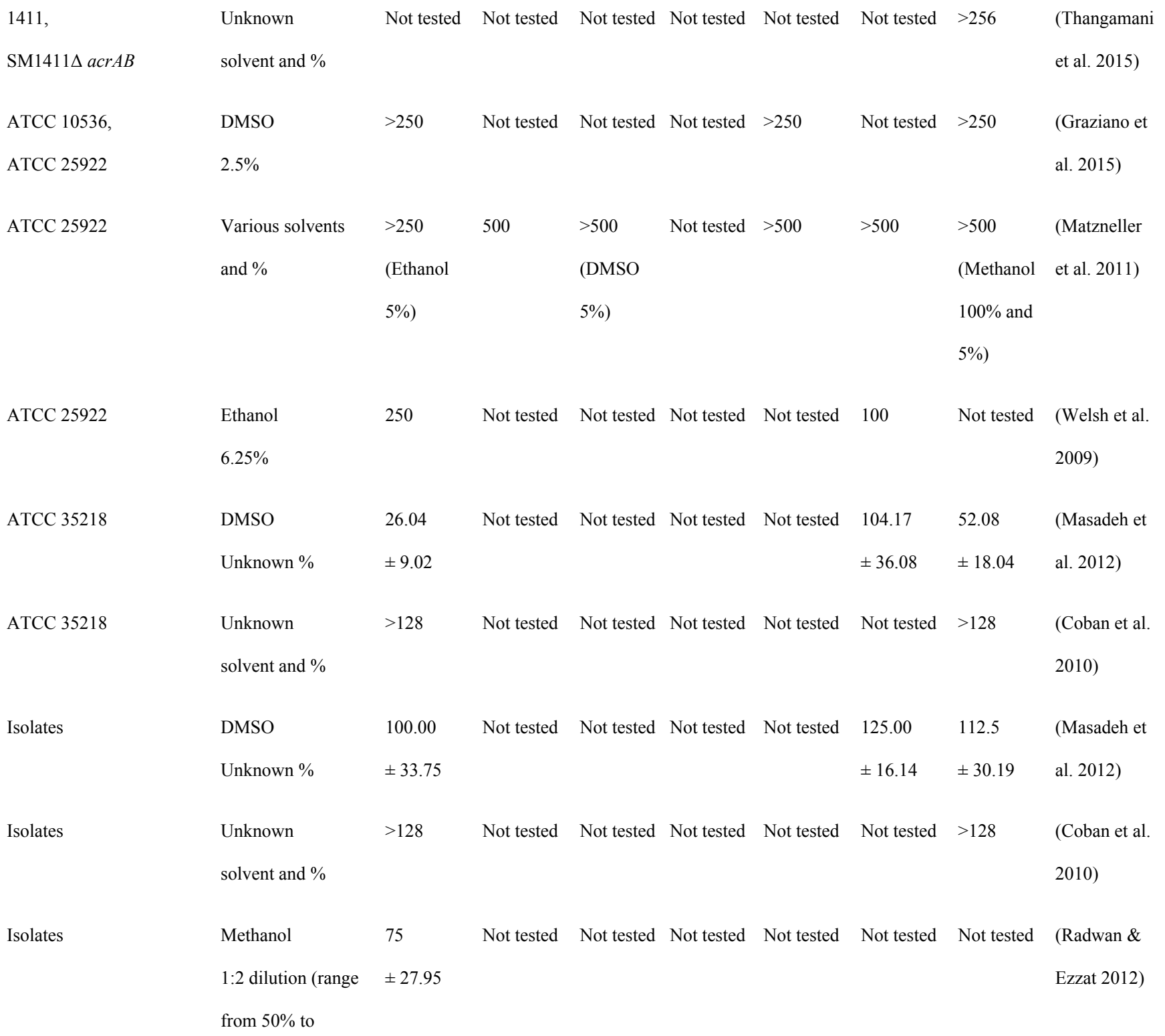

(Masadeh et

al. 2012) 
Escherichia coli 0157:H7

ATCC 35150 ,

ATCC 700728

Haemophilus influenzae

Isolates

Isolates

DMSO

$2.5 \%$

\section{Klebsiella species}

Not specified

Ethanol

$1 \%$

Klebsiella pneumoniae

ATCC 13883

ATCC 700603

DMSO

Unknown \%

Unknown

solvent and $\%$

ATCC BAA-1705,

ATCC BAA-2146

Isolates

Isolates

Unknown

solvent and \%
ATCC 29247

Not tested Not tested Not tested Not tested Not tested Not tested $>256$

(Thangamani

et al. 2015)

\begin{tabular}{|c|c|c|c|c|c|c|}
\hline Not tested & Not tested & Not tested & Not tested & 166.67 & 52.08 & (Masadeh et \\
\hline & & & & \pm 72.16 & \pm 18.04 & al. 2012) \\
\hline Not tested & Not tested & Not tested & Not tested & 366.67 & 145.83 & (Masadeh et \\
\hline & & & & \pm 0.00 & \pm 32.27 & al. 2012) \\
\hline
\end{tabular}

Not tested $>100 \quad$ Not tested Not tested $>100 \quad$ Not tested $>250$

(Bergman et

al. 2011)

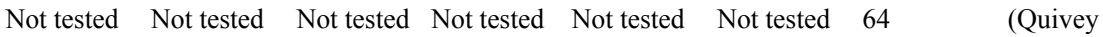

2014)

\begin{tabular}{|c|c|c|c|c|c|c|c|}
\hline 67 & Not tested & Not tested & Not tested & Not tested & 333.33 & 166.67 & (Masadeh et \\
\hline .16 & & & & & \pm 144.33 & \pm 72.16 & al. 2012) \\
\hline 8 & Not tested & Not tested & Not tested & Not tested & Not tested & $>128$ & $\begin{array}{l}\text { (Coban et al. } \\
2010)\end{array}$ \\
\hline tested & Not tested & Not tested & Not tested & Not tested & Not tested & $>256$ & $\begin{array}{l}\text { (Thangamani } \\
\text { et al. 2015) }\end{array}$ \\
\hline $\begin{array}{l}16.67 \\
51.03\end{array}$ & Not tested & Not tested & Not tested & Not tested & $\begin{array}{l}258.33 \\
\pm 64.55\end{array}$ & $\begin{array}{l}241.67 \\
\pm 60.38\end{array}$ & $\begin{array}{l}\text { (Masadeh et } \\
\text { al. 2012) }\end{array}$ \\
\hline 8 & Not tested & Not tested & Not tested & Not tested & Not tested & $>128$ & $\begin{array}{l}\text { (Coban et al. } \\
2010)\end{array}$ \\
\hline
\end{tabular}

Moraxella catarrhalis

Isolates

DMSO
Not tested 15.6

(Bergman et 
Porphyromonas gingivalis

ATCC 33277

DMSO

Not tested

Not tested

$1 \%$ stock,

Brain heart

infusion broth

\section{Proteus mirabilis}

ATCC 12459

Isolates

Isolates

Methanol

1:2 dilution (range

62.5

Unknown \%

$\pm 0.00$

\section{Not tested}

Not tested Not tested Not tested

250

166.67

$\pm 0.00 \quad \pm 72.16$

from $50 \%$ to

$0.78 \%)$

Pseudomonas aeruginosa

ATCC 9027

ATCC 9027,

ATCC 9721,

DMSO

127.08

Not test

$\pm 25.51$

125

Not tested

$\pm 0.00$

(Emani et al.

\begin{tabular}{|c|c|c|c|c|c|c|c|c|c|}
\hline & Unknown \% & \pm 36.08 & & & & & \pm 72.16 & \pm 72.16 & al. 2012) \\
\hline ATCC 9027, & Unknown & Not tested & Not tested & Not tested & Not tested & Not tested & Not tested & $>256$ & (Thangamani \\
\hline ATCC 9721, & solvent and $\%$ & & & & & & & & et al. 2015) \\
\hline \multicolumn{10}{|l|}{ ATCC 10145} \\
\hline \multirow[t]{2}{*}{ ATCC 15442} & Unknown & $>1024$ & $>1024$ & $>1024$ & $>1024$ & $>1024$ & $>1024$ & $>1024$ & (Thangamani \\
\hline & solvent and \% & & & & & & & & et al. 2015) \\
\hline \multirow[t]{2}{*}{ ATCC 25619} & DMSO & $>250$ & Not tested & Not tested & Not tested & $>250$ & Not tested & $>250$ & (Graziano et \\
\hline & $2.5 \%$ & & & & & & & & al. 2015) \\
\hline ATCC 25619, & Unknown & Not tested & Not tested & Not tested & Not tested & Not tested & Not tested & $>256$ & (Thangamani \\
\hline ATCC 27853 & solvent and \% & & & & & & & & et al. 2015) \\
\hline \multirow[t]{2}{*}{ ATCC 27853} & DMSO & $>250$ & Not tested & Not tested & Not tested & $>250$ & Not tested & $>250$ & (Graziano et \\
\hline & $2.5 \%$ & & & & & & & & al. 2015) \\
\hline
\end{tabular}




\begin{tabular}{|c|c|c|c|c|c|c|c|c|c|}
\hline ATCC 27853 & $\begin{array}{l}\text { Various solvents } \\
\text { and \% }\end{array}$ & $\begin{array}{l}>250 \\
\text { (Ethanol }\end{array}$ & 500 & $\begin{array}{l}>500 \\
\text { (DMSO }\end{array}$ & Not tested & $>500$ & $>500$ & $\begin{array}{l}>500 \\
\text { (Methanol }\end{array}$ & $\begin{array}{l}\text { (Matzneller } \\
\text { et al. 2011) }\end{array}$ \\
\hline & & $5 \%)$ & & $5 \%)$ & & & & $\begin{array}{l}100 \% \text { and } \\
5 \%)\end{array}$ & \\
\hline ATCC 27853 & $\begin{array}{l}\text { Ethanol } \\
6.25 \%\end{array}$ & 250 & Not tested & Not tested & Not tested & Not tested & 100 & Not tested & $\begin{array}{l}\text { (Welsh et al. } \\
\text { 2009) }\end{array}$ \\
\hline $\begin{array}{l}\text { ATCC } 35032, \\
\text { ATCC BAA- } 1744\end{array}$ & $\begin{array}{l}\text { Unknown } \\
\text { solvent and \% }\end{array}$ & Not tested & Not tested & Not tested & Not tested & Not tested & Not tested & $>256$ & $\begin{array}{l}\text { (Thangamani } \\
\text { et al. 2015) }\end{array}$ \\
\hline PAO1 & $\begin{array}{l}\text { DMSO } \\
2 \% \text { stock, } \\
\text { Lysogeny Broth }\end{array}$ & 625 & Not tested & Not tested & Not tested & Not tested & 625 & Not tested & $\begin{array}{l}\text { (Sarabhai et } \\
\text { al. 2015) }\end{array}$ \\
\hline Isolates & $\begin{array}{l}\text { DMSO } \\
\text { Unknown \% }\end{array}$ & $\begin{array}{l}95.83 \\
\pm 22.09\end{array}$ & Not tested & Not tested & Not tested & Not tested & $\begin{array}{l}291.67 \\
\pm 39.53\end{array}$ & $\begin{array}{l}120.83 \\
\pm 32.27\end{array}$ & $\begin{array}{l}\text { (Masadeh et } \\
\text { al. 2012) }\end{array}$ \\
\hline Isolates & $\begin{array}{l}\text { Unknown } \\
\text { solvent and \% }\end{array}$ & $>128$ & Not tested & Not tested & Not tested & Not tested & Not tested & $>128$ & $\begin{array}{l}\text { (Coban et al. } \\
\text { 2010) }\end{array}$ \\
\hline Unknown strain & $\begin{array}{l}\text { Ethanol } \\
1 \%\end{array}$ & Not tested & Not tested & Not tested & Not tested & Not tested & Not tested & $>256$ & $\begin{array}{l}\text { (Quivey } \\
\text { 2014) }\end{array}$ \\
\hline Salmonella Typhin & & & & & & & & & \\
\hline ATCC 700720 & $\begin{array}{l}\text { Unknown } \\
\text { solvent and \% }\end{array}$ & Not tested & Not tested & Not tested & Not tested & Not tested & Not tested & $>256$ & $\begin{array}{l}\text { (Thangamani } \\
\text { et al. 2015) }\end{array}$ \\
\hline
\end{tabular}


Figure 1

Flow chart summarizing the literature search process performed in six databases on 7 th April 2017.

CINAHL, Cumulative Index to Nursing and Allied Health Literature.

793 potential studies identified:

- $\mathrm{CINAHL}=2$

- Cochrane Library $=1$

- Embase $=34$

- PubMed $=53$

- Google Scholar $=695$

- Web of Science $=8$

37 full-text studies considered for review:

- $\mathrm{CINAHL}=1$

- Embase $=10$

- PubMed = 10

- Google Scholar $=13$

- Web of Science $=3$

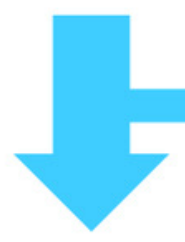

756 unrelated studies (covering drug interactions; antifungal or antiviral properties of statins; antibacterial properties of mevastatin, cerivastatin, antibiotics or natural products) excluded based on title and abstract:

- $\mathrm{CINAHL}=1$

- Cochrane Library $=1$

- Embase $=24$

- PubMed $=43$

- Google Scholar $=682$

- Web of Science $=5$

16 studies included for current review article

21 studies were excluded:

- 18 duplicate studies

- 1 review covered 8 duplicate studies

- 1 study did not test direct bacterial exposure

- 1 study did not test individual statin exposure 


\section{Figure 2}

Potential of statins as repurposed novel adjuvant antibiotics for infections in the statinbacteria-human-environment continuum.

(+) refers to factors leading to potentially positive outcomes, whereby statins coadministered with antibiotics may impede AMR (AMR breakers). (-) refers to factors leading to potentially negative outcomes, whereby statin use may favor selective pressures or coselection for resistance and culminate in AMR (AMR makers). (?) refers to further research required to bridge knowledge gap. AMR, antimicrobial resistance; MIC, minimum inhibitory concentration; NET, neutrophil extracellular trap.

\section{Humans}

(+) Enhanced host immunity

(?) NET production

(?) Pleiotropic effects in sepsis

(?) Nuclear receptor agonists

(+) Improved wound healing

(-) Dysbiosis of gut microbiota

(-) Statin plasma concentrations in bacteremic patients $<$ MIC

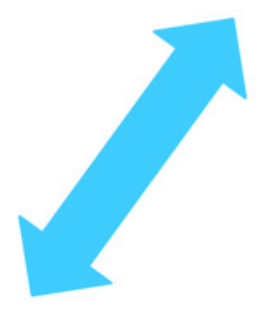

Statins

(+) Intrinsic antibacterial activity

(?) Contribution as AMR makers via selective pressures or co-selection

(?) Mechanism of antibacterial action

\section{Bacteria}

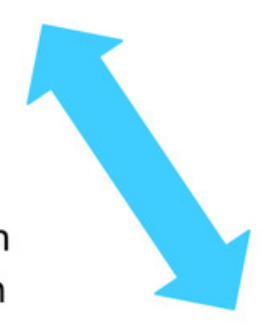

$(+)$ Synergistic antibiotic effects

(+) Attenuated virulence factors

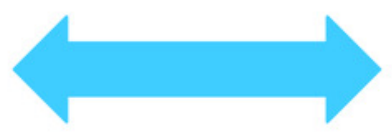

(-) Extensive use of statins

(-) Subinhibitory concentrations

(-) Persistence in sewage 


\section{Figure 3}

Chemical structures of clinically used statins and selected non-antibiotic drugs from other pharmacological classes.

(A) Type 1 statins (SMV, LVS, and PRV) are derived from fungi and have similar chemical structures. (B) Type 2 statins (ATV, FLV, PTV, and RSV) are synthetic compounds which bind more tightly with HMG-CoA reductase. (C) Selected non-antibiotic drugs from other pharmacological classes with antibacterial activity against Staphylococcus aureus. The dihydroxy acid moiety (in PRV, ATV, FLV, PTV, and RSV) is required for HMG-CoA reductase inhibition, while the lactone group (in SMV and LVS) must by metabolised to the dihydroxy acid moiety before HMG-CoA reductase inhibition may occur. Drugs marked ( $\dagger$ ) possess antibacterial activity against Staphylococcus aureus. Two methyl groups arranged in a tetrahedral (*) or similar trigonal pyramidal (\#) molecular geometry may be important for such antibacterial activity. ATV, atorvastatin; FLV, fluvastatin; HMG-CoA, 3-hydroxy-3methylglutaryl-coenzyme A; LVS, lovastatin; PRV, pravastatin; PTV, pitavastatin; RSV, rosuvastatin; SMV, simvastatin. 
(A)

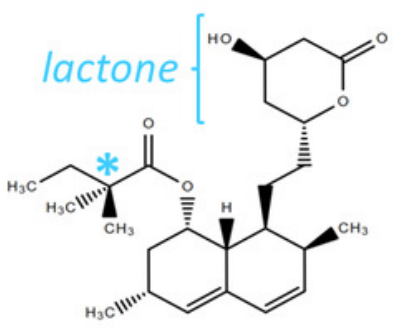

Simvastatin ${ }^{\dagger}$

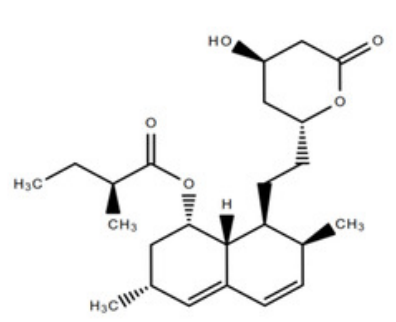

Lovastatin

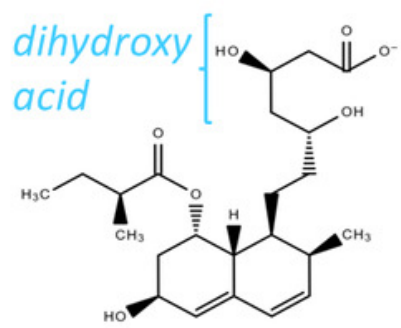

Pravastatin

(B)

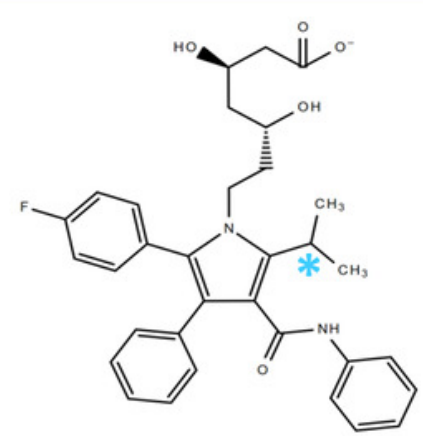

Atorvastatin $^{+}$

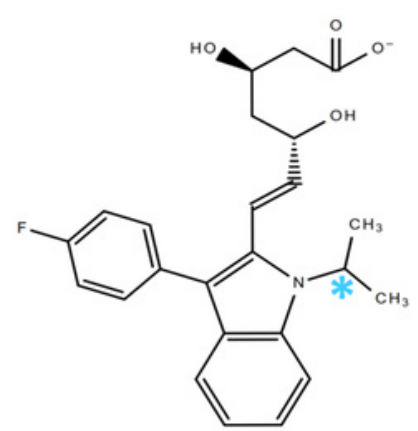

Fluvastatin ${ }^{\dagger}$<smiles>C[C@@H](CC(=O)O)C[C@@H](O)/C=C/c1c(C2CC2)nc2ccccc2c1-c1ccc(I)cc1</smiles>

Pitavastatin

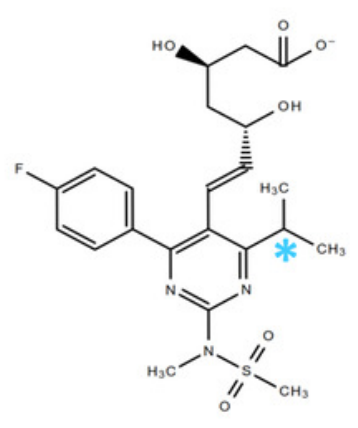

Rosuvastatin ${ }^{\dagger}$

(C)<smiles>CN(C)CCC=C1c2ccccc2CCc2ccccc21</smiles>

Amitriptyline ${ }^{\dagger}$ (antidepressant)<smiles>CN(C)CCCN1c2ccccc2Sc2ccc(Cl)cc21</smiles>

Chlorpromazine ${ }^{\dagger}$ (antipsychotic)<smiles>CC(C)NCC(O)COc1cccc2ccccc12</smiles>

Propranolol $^{\dagger}$ (antihypertensive)<smiles>CN(C)CCOc1ccc(C(=C(CO)c2ccccc2)c2ccccc2)cc1</smiles>

Tamoxifen $^{\dagger}$ (anticancer) 